\title{
Identification of iron and heme utilization genes in Aeromonas and their role in the colonization of the leech digestive tract
}

\section{OPEN ACCESS}

Edited by:

Shana Goffredi,

Occidental College, USA

Reviewed by:

John M. Chaston,

Brigham Young University, USA

Mark Mandel,

Northwestern University Feinberg

School of Medicine, USA

*Correspondence:

Joerg Graf,

Department of Molecular and Cell Biology, University of Connecticut,

91 N. Eagleville Rd., Storrs,

CT 06269, USA

joerg.graf@uconn.edu

${ }^{\dagger}$ Present Address:

Barbara L. Levarge,

Harvard Medical School, Boston, USA

Specialty section:

This article was submitted to

Microbial Symbioses,

a section of the journal

Frontiers in Microbiology

Received: 16 May 2015

Accepted: 13 July 2015

Published: 28 July 2015

Citation:

Maltz M, LeVarge BL and Graf J (2015) Identification of iron and heme utilization genes in Aeromonas and their role in the colonization of the leech digestive tract.

Front. Microbiol. 6:763.

doi: 10.3389/fmich.2015.00763

\author{
Michele Maltz, Barbara L. LeVarge ${ }^{\dagger}$ and Joerg Graf * \\ Department of Molecular and Cell Biology, University of Connecticut, Storrs, CT, USA
}

It is known that many pathogens produce high-affinity iron uptake systems like siderophores and/or proteins for utilizing iron bound to heme-containing molecules, which facilitate iron-acquisition inside a host. In mutualistic digestive-tract associations, iron uptake systems have not been as well studied. We investigated the importance of two iron utilization systems within the beneficial digestive-tract association Aeromonas veronii and the medicinal leech, Hirudo verbana. Siderophores were detected in $A$. veronii using chrome azurol S. Using a mini Tn5, a transposon insertion in viuB generated a mutant unable to utilize iron using siderophores. The $A$. veronii genome was then searched for genes potentially involved in iron utilization bound to heme-containing molecules. A putative outer membrane heme receptor ( $h g p B)$ was identified with a transcriptional activator, termed $h g p R$, downstream. The $h g p B$ gene was interrupted with an antibiotic resistance cassette in both the parent strain and the viuB mutant, yielding an $h g p B$ mutant and a mutant with both iron uptake systems inactivated. In vitro assays indicated that $h g p B$ is involved in utilizing iron bound to heme and that both iron utilization systems are important for $A$. veronii to grow in blood. In vivo colonization assays revealed that the ability to acquire iron from heme-containing molecules is critical for $A$. veronii to colonize the leech gut. Since iron and specifically heme utilization is important in this mutualistic relationship and has a potential role in virulence factor of other organisms, genomes from different Aeromonas strains (both clinical and environmental) were queried with iron utilization genes of $A$. veronii. This analysis revealed that in contrast to the siderophore utilization genes heme utilization genes are widely distributed among aeromonads. The importance of heme utilization in the colonization of the leech further confirms that symbiotic and pathogenic relationships possess similar mechanisms for interacting with animal hosts.

Keywords: iron, heme, siderophore, symbiosis, virulence factor, Aeromonads 


\section{Introduction}

Bacteria-host interactions can manifest many different outcomes. These outcomes can range from the commonly investigated pathogenic ones, in which microbes have a negative effect on a host, to mutualistic interactions, in which both microbe and host benefit. Despite the disparity in the end result, some studies have revealed a similarity in the molecular requirements of pathogenic and beneficial relationships (Hentschel et al., 2000; Steinert et al., 2000; Falkow, 2004; Silver et al., 2007a). A better understanding of colonization factors in mutualistic symbioses can lead to a clearer perception of conserved processes underlying microbe -microbe and microbe-host interactions.

The medicinal leech, Hirudo verbana, is a freshwater parasite that feeds exclusively on vertebrate blood. During a single feeding, the medicinal leech can consume over five times its body weight, after which the blood is stored in the largest compartment of the digestive tract, the crop (Sawyer, 1986). The leech modifies the ingested blood meal by removing water and osmolytes from each meal (Sawyer, 1986). The complement system of the ingested blood meal remains active for some time preventing sensitive bacteria from colonizing the intraluminal fluid (ILF) (Indergand and Graf, 2000; Braschler et al., 2003). In addition, leech hemocytes, macrophage-like cells of invertebrates, infiltrate the crop and phagocytose sensitive bacteria (Silver et al., 2007b). Within ILF of the crop, the digestive-tract symbionts reside and proliferate. The symbionts require many molecular tools for successful colonization and persistence within this environment (Graf, 2006; Silver et al., 2007a; Nelson et al., 2012). These molecular tools can be critical during the first $24 \mathrm{~h}$ of incubation, especially the ability of $A$. veronii to lyse erythrocytes (Maltz and Graf, 2011). All of these features help to maintain the leech gut as a simple microbial community, dominated by two species, Aeromonas veronii and Mucinivorans hirudinis (Graf, 1999a; Worthen et al., 2006; Nelson et al., 2015). A. veronii, a Gram-negative, facultative anaerobe, is both a symbiont of $H$. verbana and a human pathogen. It can cause diseases such as septicemia, wound infections, and gastroenteritis (Janda et al., 1984, 2010; Janda and Abbott, 1998, 2010; Senderovich et al., 2008). M. hirudinis is Gram-negative, an obligate anaerobe and represents a new genus Mucinivorans in the Bacteroidetes family that was in previous studies referred to as a Rikenellalike bacterium (Worthen et al., 2006). The simplicity of the leech gut microbiome and the ability to genetically manipulate A. veronii allows one to study factors important for microbemicrobe interactions and microbe-host interactions in a naturally occurring mutualistic symbioses (Graf, 2006).

In blood, low levels of free iron are present because most iron is bound to specialized iron-binding proteins, such as transferrin in plasma or hemoglobin inside erythrocytes (Crosa, 1989; Barghouthi et al., 1991; Crosa and Walsh, 2002). Most microorganisms require iron for metabolic processes and have evolved sophisticated mechanisms to obtain protein-associated iron with in a host (Crosa, 1989; Litwin and Calderwood, 1993; Crosa and Walsh, 2002). These mechanisms can be divided into siderophore-dependent and siderophore-independent iron acquisition systems (Byers et al., 1991).
Siderophores are low-molecular weight iron chelators that microbes secrete into the environment under iron-limiting conditions. In many bacteria, the ferric uptake regulator, Fur, regulates siderophore biosynthesis (Crosa, 1989; Crosa and Walsh, 2002). Siderophores can have a very high affinity for iron, enabling microbes to obtain iron in the presence of transferrin or free iron found in the environment. Once iron is bound to the siderophore, the iron-siderophore complex associates with a siderophore receptor located on the outer membrane of cell and is transported into the cytoplasm in an ATP-dependent manner. In the cytoplasm, the iron is dissociated from the ironsiderophore complex and used for cellular processes (Crosa, 1989; Zywno et al., 1992; Crosa and Walsh, 2002). Escherichia coli Fes and Vibrio cholerae ViuB are esterases that hydrolyze the ligand, releasing iron (Butterton and Calderwood, 1994).

Some microbes also have receptors specialized for obtaining host-produced iron-containing molecules such as transferrin or heme (Byers et al., 1991). This process of iron acquisition is siderophore-independent. For example, the heme receptor has a high affinity for heme, enabling microbes to bind heme and subsequently dissociate iron from heme. In Gram-negative bacteria, a heme receptor located in the outer membrane binds to heme and heme is translocated into the cytoplasm in a TonB dependent manner (Stojiljkovic and Perkins-Balding, 2002).

Iron utilization has been shown to be an important virulence factor in several pathogenic associations, including Haemophilus influenzae, V. cholerae, Yersinia spp., and Corynebacterium diphtheriae (Litwin and Calderwood, 1993; Morton et al., 2007, 2009). However, in beneficial symbioses, only a few systems have shown iron utilization as an important colonization factor; e.g., Rhizobium leguminosarum, Sodalis glossinidius, and Vibrio fischeri (Nadler et al., 1990; Graf and Ruby, 2000; Hrusa et al., 2015). Aeromonas species have been shown to posses at least two different iron utilization mechanisms, siderophores and a receptor for heme-containing molecules (Barghouthi et al., 1989a,b). Under iron limiting conditions Aeromonads can produce one of two siderophores, either enterobactin or a set of four bis-catecholate siderophores named amonabactin (Telford et al., 1994). It remains unclear whether Aeromonas species use one or both of these iron utilization mechanisms during infection or symbiosis. In this study we determined that an A. veronii strain isolated from the leech crop, HM21, possess two high-affinity iron-utilization systems. Our goal was to determine whether one or both of these iron acquisition systems are important for $A$. veronii to colonize the leech digestive tract. We evaluated the importance of siderophore acquisition and heme utilization by generating mutants and double mutants and characterizing these strains. We also examined the prevalence iron uptake systems in other Aeromonas species.

\section{Materials and Methods}

\section{Bacterial Strains and Growth Conditions}

The A. veronii strains were cultured at $30^{\circ} \mathrm{C}$ and Escherichia coli at $37^{\circ} \mathrm{C}$ in Luria broth (LB) (Sambrook and Russell, 2001), or low iron medium (LIM) (Cox, 1994) or LB agar plates ( $15 \mathrm{~g} / \mathrm{l}$ of BactoAgar). For experiments requiring low iron levels, 
glassware was acid washed overnight in $6 \mathrm{M} \mathrm{HCl}$ or new plastic ware was used (Cox, 1994). The concentrated 5xM9 salts were prepared by dissolving, per liter, $30 \mathrm{~g} \mathrm{Na}_{2} \mathrm{HPO}_{4}, 15 \mathrm{~g} \mathrm{KH}_{2} \mathrm{PO}_{4}$, $5 \mathrm{~g} \mathrm{NH}_{4} \mathrm{Cl}$, and $2.5 \mathrm{~g} \mathrm{NaCl}$. M9-based (Sambrook and Russell, 2001) LIM was prepared by adding the following to $748 \mathrm{ml}$ of Nanopure (Barnstead, Dubuque, IA) water: $200 \mathrm{ml} 5 \mathrm{xM} 9$ salts, $20 \mathrm{ml} 20 \%$ glucose, and $30 \mathrm{ml} 10 \%$ Bacto $^{\mathrm{TM}}$ casamino acids. Residual iron was removed by adding Chelex ${ }^{\circledR} 100$ Resin (BioRad, Hercules, CA) at a concentration of $100 \mathrm{~g} / \mathrm{l}$ medium. The resin was stirred with the medium for $1 \mathrm{~h}$. Afterwards, the medium was filtered into acid-washed glassware. The $\mathrm{pH}$ of the LIM was adjusted to $\mathrm{pH} 7.0$ with $\mathrm{HCl}$. The medium was filter sterilized $(0.2 \mu \mathrm{m})$ and $\mathrm{MgSO}_{4}(2 \mathrm{ml} / \mathrm{l})$ and $\mathrm{CaCl}_{2}$ $(0.1 \mathrm{ml} / \mathrm{l})$ were aseptically added. Chelex ${ }^{\circledR} 100$ Resin was restored and reused as recommended by the manufacturer; used resin was stirred for $1 \mathrm{~h}$ in two volumes of $1 \mathrm{M} \mathrm{HCl}$. The resin was filtered and washed in 5 volumes Nanopure water, followed a rinse with 2 volumes $1 \mathrm{M} \mathrm{NaOH}$. After the $\mathrm{NaOH}$ was removed, the resin was subjected to numerous $30 \mathrm{~min}$ long, 5-volume washes in Nanopure water. These rinses were repeated until the resin suspension had a $\mathrm{pH}$ between 10 and 11 , and the resin was subsequently air-dried. For LIM plates, water was replaced with agar cooled to $50^{\circ} \mathrm{C}$. The growth medium was supplemented with the appropriate antibiotics at the following concentrations: ampicillin, $100 \mu \mathrm{g} / \mathrm{ml}$; chloramphenicol $(\mathrm{Cm})$, $1 \mu \mathrm{g} / \mathrm{ml}$ for $A$. veronii and $30 \mu \mathrm{g} / \mathrm{ml}$ for $E$. coli; kanamycin $(\mathrm{Km}), 100 \mu \mathrm{g} / \mathrm{ml}$; rifampin (Rf), $100 \mu \mathrm{g} / \mathrm{ml}$ for selection and $10 \mu \mathrm{g} / \mathrm{ml}$ for maintenance; streptomycin (Sm), $100 \mu \mathrm{g} / \mathrm{ml}$; and trimethoprim (Tp), $100 \mu \mathrm{g} / \mathrm{ml}$.

\section{Generation of $\boldsymbol{A}$. veronii Siderophore Mutants}

The A. veronii siderophore mutants were derived from HM21R (Table 1) by conjugation with E. coli strain BW20767 harboring pRL27, which carries a miniTn5, as described previously (Larsen et al., 2002; Silver et al., 2007a,b; Maltz and Graf, 2011). Thousand nine hundred mutants were screened on CAS (chrome azurol S) (Km, Rf) agar plates for color changes of the medium surrounding the colonies. CAS is an iron-dye complex that changes color from blue to orange when iron is dissociated from CAS. CAS (Km, Rf) agar plates were prepared as previously described by Schwyn and Neilands (1987; Neilands, 1994).

\section{EDDA Inhibition Assay}

The mutants were tested for the ability to obtain iron in the presence of the iron chelator ethylenediamine-di ( $o$ hydroxyphenlacetic acid), EDDA, by adding EDDA for a final concentration of $150 \mu \mathrm{M}$ in LIM or LIM plates. All cultures were grown for $24 \mathrm{~h}$ at $30^{\circ} \mathrm{C}$. Heme at a final concentration of $50 \mu \mathrm{M}$ was added to broth containing an inhibiting concentration of EDDA $(150 \mu \mathrm{M})$ (Crosa and Walsh, 2002).

\section{Molecular Characterization Siderophore Utilization Mutant}

The site of the transposon insertion was determined by extracting DNA from the mutant, digested using EcoRI selfligating and electroporating the DNA into E. coli strain S17$1 \lambda$ pir. DNA was extracted using DNeasy Blood \& Tissue kit (Qiagen Valencia, CA). The resulting plasmid (pBBL3) was sequenced using outward facing primers for miniTn5 (tpnRL17-1 AACAAGCCAGGGATGTAACG and tpnRL132 CAGCAACACCTTCTTCACGA). A BLASTX search of the NCBI database identified presumptive homologs. The A. veronii genome was then searched for the presumptive homologs.

\section{Construction of $\boldsymbol{A}$. veronii Heme Receptor Mutants}

The $A$. veronii genome was searched for a gene encoding a heme receptor by comparing the presumptive heme receptor, $\operatorname{HgpB}$, from $A$. hydrophila to the deduced amino acid sequence of the genome using BLASTX (Bomar et al., 2013). A $1.5 \mathrm{~kb}$ fragment containing the presumptive heme receptor gene $(h g p B)$ was PCR amplified from Hm21 DNA using primers hgpB1F 5'CGTAT TTGACCCGAGCATC' 3 and hgpB2R 5'TCTAATCATGGGATC TCACGGC'3. The reaction mixture contained $100 \mathrm{ng}$ of DNA, $5 \mu \mathrm{l}$ PCR buffer, $1.5 \mathrm{mM} \mathrm{MgCl}_{2}, 200 \mu \mathrm{M}$ each dNTP, $0.2 \mu \mathrm{M}$ each primer, and $1 \mathrm{U}$ of Platinum Taq DNA polymerase (Invitrogen, Carlsbad, CA) in a final volume of $50 \mu \mathrm{l}$. The amplification conditions were as follows: (i) $5 \mathrm{~min}$ at $95^{\circ} \mathrm{C}$; (ii) 30 cycles of $30 \mathrm{~s}$ at $95^{\circ} \mathrm{C}, 30 \mathrm{~s}$ at $60^{\circ} \mathrm{C}$, and $90 \mathrm{~s}$ at $72^{\circ} \mathrm{C}$. The PCR product was cloned into $\mathrm{pCR}^{\circledR} 2.1$ using a TA Cloning $\left.{ }^{(}\right)$Kit (Invitrogen, Carlsbad, CA) yielding pMM2. The identity of the insert as $h g p B$ was confirmed by DNA sequencing. A chloramphenicol $(\mathrm{Cm})$ cassette was amplified from $\mathrm{pBCSK}+/-$ (Stratagene) using the following primers with added SalI restriction sites, CMF1 5'CGAGTCGACTCCAACTTTCACCATAATGA' 3 and CMR1 5'CTAGTCGACGATCTCAACAGCGGTAAGAT'3. The reaction mixture was as described above except that $1 \mathrm{mM}$ $\mathrm{MgCl}_{2}$ and $0.5 \mu \mathrm{M}$ of each primer were present in the reaction mix. The amplification conditions were the same as described above except the annealing temp was $70^{\circ} \mathrm{C}$. The $\mathrm{Cm}^{\mathrm{R}}$ cassette PCR product was inserted into $\mathrm{pCR}^{\circledR} 2.1$ using a TA Cloning ${ }^{\complement}$ Kit yielding pMM1. The $\mathrm{Cm}^{\mathrm{R}}$ cassette was then excised from pMM1 using SalI and inserted into a SalI site in the middle of $h g p B$ yielding pMM3. The interrupted gene was moved from pMM3 into pKAS46 using EcoRI yielding pMM4 (Skorupski and Taylor, 1996).

The A. veronii $h g p B$ mutants were derived from HM21RS and S-497S (Table 1). HM21RS and S-497S are spontaneous streptomycin resistant mutants from HM21R and S-497, respectively. In a tri-parental mating with the helper plasmid pEVS104, the suicide plasmid pMM4 was moved into either HM21RS or S-497S yielding a heme receptor mutant (H-890) and a siderophore/heme receptor double mutant (SH-894), respectively. For the conjugations, $5 \times 10^{7} \mathrm{CFU}$ of each donor and $1 \times 10^{8} \mathrm{CFU}$ of the recipient cells were mated overnight and double cross-over events were selected for by plating on LB Sm $100 \mu \mathrm{g} / \mu \mathrm{l} \mathrm{Cm1} \mu \mathrm{g} / \mu \mathrm{l}$, because pMM4 carries an $r p s L$ allele that confers dominant sensitivity to $\mathrm{Sm}$. The presumptive mutants were verified with PCR using hgpB1F and hgpB2R primers, comparing the size of the PCR product amplified from the mutants to $\mathrm{Hm} 21$, as previously described (Rio et al., 2007). 
TABLE 1 | Bacterial strains and plasmids.

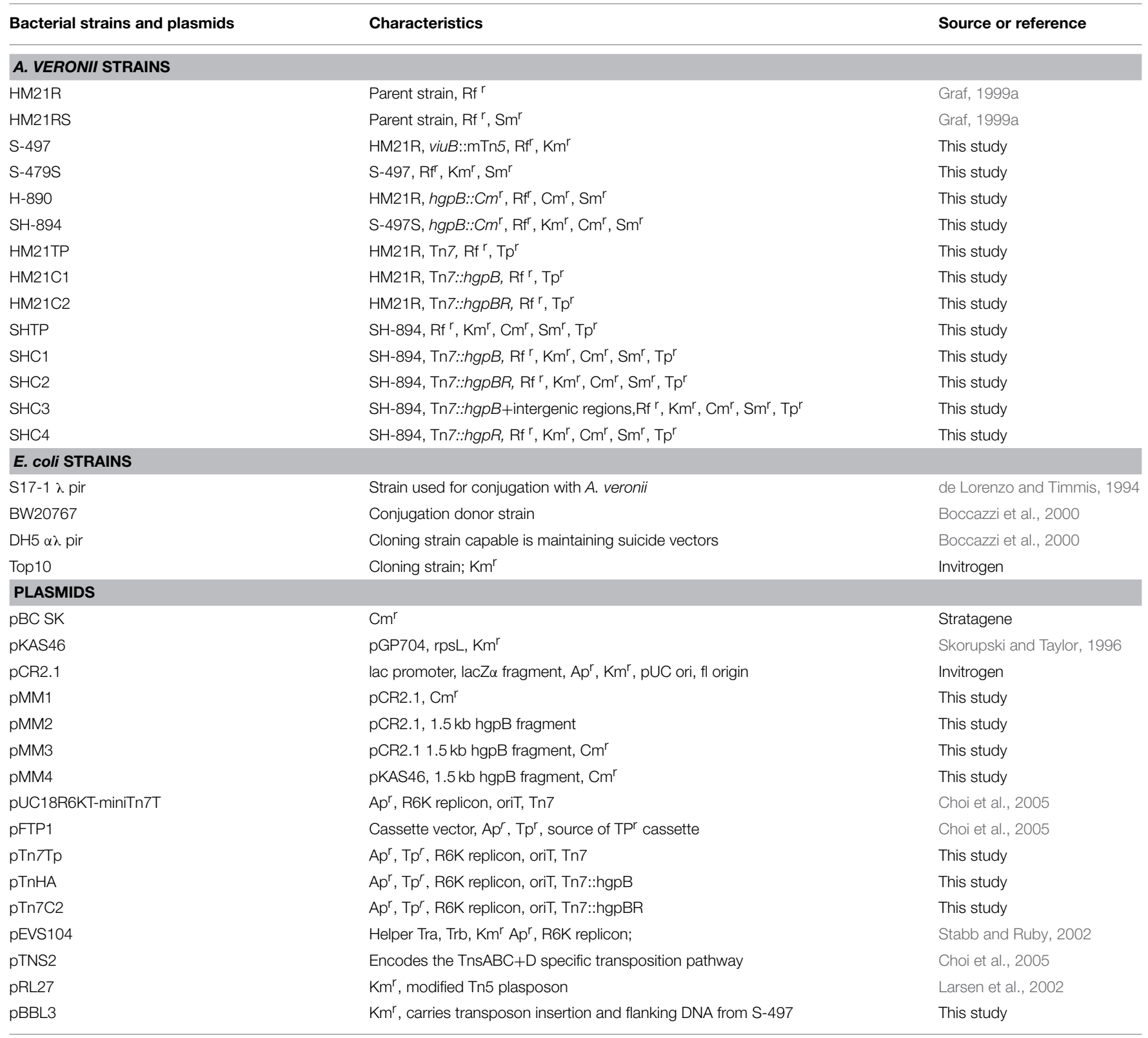

Colonization Assay Method and Blood In vitro Assays The ability of the mutants to colonize the crop of $H$. verbana was done as described previously (Graf, 1999b; Rio et al., 2007; Silver et al., 2007b), with following modifications. Each of the strains was added to $5 \mathrm{ml}$ of sheep blood (500 CFU/ml)from which $500 \mu \mathrm{l}$ were removed for the in vitro assay and the remainder was fed to a leech. During iron restoration experiments, a final concentration of $150 \mu \mathrm{M}$ of EDDA and/or $160 \mu \mathrm{M}$ of $\mathrm{FeCl}_{3}$ were added to the blood meals along with strains. The inoculated blood and the leech were incubated at room temperature for a time course of $18,24,42$, and $72 \mathrm{~h}$. The leech was sacrificed and the ILF and blood samples were plated on LB agar Rf. Differences in the colonization levels were analyzed using GraphPad Prism software. The Mann-Whitney $t$-test was performed to calculate p-values.

\section{Genetic Restoration of $A$. veronii Heme Utilization Defect}

The SH-894 double mutant was complemented using Tn7. A trimethoprim cassette was excised from pFTP1 with BamHI (NEB), gel extracted using QIAquick Gel Extraction Kit (Qiagen), and cloned into pUC18R6KT- mini-Tn7T using the BamHI site located inside the Tn7, yielding pTn7Tp (Choi et al., 2005). The following genes were PCR amplified from HM21 genomic DNA: $h p g B$ gene, $h g p B+h g p R$ together, and $h g p R$. The following primer sets were used for amplification: 
for $h p g B$ amplification-HgpR 5'CACCCATTGTAAAGAATT $\mathrm{AC}^{\prime} 3$ and HgpF 5'CAGGGCGACGACAGTGTAAAACC' 3 , for amplification of both genes $(h g p B+h g p R)-$ Trans + HgpBR $5^{\prime}$ GTAGTCGCTCGGATAGTT' 3 and Trans + HgpBF $5^{\prime}$ ATG TCATCACATCACTGG' 3 , and for amplification of hpgB onlyAHyFR 5'TTCAACCTGTTTGACAAGGA' 3 and AhyRR 5'ACG TAATGAGCAAGCTTTTG 3 . The reaction mixture contained a final concentration of $100 \mathrm{ng}$ of DNA template, $1 \mathrm{X} \mathrm{GoTaq}{ }^{\circledR}$ Green Master Mix (Promega), $1 \mu \mathrm{M}$ of either primer set in a final volume of $25 \mu$ l. The amplification conditions were as follows: (i) $5 \mathrm{~min}$ at $95^{\circ} \mathrm{C}$; (ii) 30 cycles of $30 \mathrm{~s}$ at $95^{\circ} \mathrm{C}, 30 \mathrm{~s}$ at $60^{\circ} \mathrm{C}$, and $2 \mathrm{~min}$ at $72^{\circ} \mathrm{C}$. The PCR product was cloned into $\mathrm{PCR}{ }^{\circledR} 2.1$ using the TA Cloning ${ }^{\circledR}$ Kit (Invitrogen). $h g p B$ or $h g p R$ or $h g p B$ $+h g p R$ was then digested out of pCR2.1 using EcoRI restriction sites and cloned into pTn7TP using EcoRI restriction sites located on the Tn7 yielding pTn7C1 and pTn7C2. Quad-parental matings were performed to conjugally transfer the transposon containing no insert, $\mathrm{p} \operatorname{Tn} 7 \mathrm{TP}$; $h g p B, \mathrm{p} \operatorname{Tn} 7 \mathrm{C} 1$; or $h g p B$ and hgpR, pTn7C2; hgpR, pTN7C3 into Hm21 or SH-894 yielding HM21TP, HM21C1, SHTP, SHC1, SHC2, SHC4, respectively (Table 1 and Figure 2A). The two additional plasmids need for the quad-parental matings were, pEVS104, which encodes tra genes and pTNS2 that carries the Tn7 transposase. The plasmid pTNS2 does not encode tnsE, making the transposition specific for insertion into the $g \ln S$ region of the chromosome (Choi et al., 2005). The insertion of $\operatorname{Tn} 7$ downstream of $g l n S$ was verified (Choi et al., 2005) using inverse PCR (Ochman et al., 1988). Genomic DNA was extracted from Hm21TP, Hm21C1, SHTP, SHC1, HM21C2, and SHC2 using MasterPure DNA Purification Kit (Epicentre Biotechnologies). Genomic DNA was digested using $\mathrm{NcoI}$ (New England Biolabs) overnight at $37^{\circ} \mathrm{C}$. A selfligation was preformed on the digests using T4 DNA ligase (New England Biolabs). PCR reaction mixture contained $2 \mu$ l ligation reaction, $1 \mathrm{X} \mathrm{GoTaq}{ }^{\circledR}$ Green Master Mix (Promega), $1 \mu \mathrm{M}$ Tn7R and Tn7L (Choi et al., 2005) in a final volume of $25 \mu \mathrm{l}$. PCR products were sequenced as described below using $\mathrm{Tn} 7 \mathrm{R}$ and Tn7L primers.

\section{DNA Sequencing and Sequence Analysis}

DNA Sequencing and analysis was performed as previously described in Silver et al. (2007b). The DNA sequences obtained in this study were deposited in GenBank under the accession numbers HM569268 and HM569269.

\section{Reverse Transcription PCR (RT-PCR) and Quantitative Reverse Transcription PCR (qRT-PCR)}

For both RT-PCR and qRT-PCR, RNA was isolated using Epicentre MasterPure RNA purification kit (Epicentre Biotechnologies, Madison, WI). After RNA was isolated the TURBO DNA-free kit (Ambion, Austin, TX) was used to remove any remaining DNA. The absence of DNA was confirmed by performing the PCR amplification without the reverse transcriptase on each sample using hgpB1F and hgpB2R primers. The reaction mixture contained $1.5 \mu$ l RNA template, 1x GoTaq ${ }^{\circledR}$ Green Master Mix (Promega), $1 \mu \mathrm{M}$ hgpB1F and hgpB2R in a final volume of $25 \mu \mathrm{l}$. cDNA was synthesized using SuperScript III First-strand Synthesis SuperMix (Invitrogen).
The reaction mixture contained $5 \mu \mathrm{l}$ RNA, $1 \mu \mathrm{l}$ random hexamers, $1 \mu \mathrm{l}$ annealing buffer, $2 \mu \mathrm{l}$ enzyme mix, $10 \mu \mathrm{l}$ firststrand mix, and $1 \mu \mathrm{l}$ in a final volume of $20 \mu \mathrm{l}$. Following first-strand cDNA synthesis for RT-PCR, PCR was performed using GoTaq ${ }^{\circledR}$ Green Master Mix, equal amounts of cDNA was used. For both RT-PCR and qRT-PCR the primer used were: for $h p g R$ (Trans.activatorR $5^{\prime}$ CGTGCCAGGGAATCGTGAT C3', Trans.activatorF 5'AGGACATCGCTGGGTTGG3'), $h g p B$ (HemeF1 5'TTGAGCTTGACCGCATCCGG3', HemeR1 5'GGT GAAGTGGAGAACCTGCTGC $3^{\prime}$ ), and $r p o B$ (rpoBF $5^{\prime}$ TTA TCGTCTCCAGCTGCACCG3', rpoBR 5'TGCTGGCAGTTT GCGACGAC3 ${ }^{\prime}$ ). For qRT-PCR a reaction mix was set up using Sso Advanced ${ }^{\mathrm{TM}}$ Universal SYBR ${ }^{\circledR}$ Green Supermix and the CFX96-Real Time system (Bio-Rad Laboratories, Hercules, CA). The reaction mix contained $5 \mu l$ Sso Advanced ${ }^{\mathrm{TM}}$ Universal SYBR $^{\circledR}$ Green Supermix, $1.5 \mu l$ forward primer, 1.5 reverse primer, $1 \mu \mathrm{l} \mathrm{cDNA}$ and $1 \mu \mathrm{l} \mathrm{H}_{2} \mathrm{O}$ for a final volume of $10 \mu \mathrm{l}$. Quantitative measurements were performed on biological samples in triplicate and results were normalized to HM21 housekeeping gene $r p o B$.

\section{Genomic Analysis of Other Aeromonas Strains}

Genomes were downloaded from NCBI and annotated with RAST as previously described (Aziz et al., 2008; Colston et al., 2014) and the iron utilization genes from A. veronii $\operatorname{Hm} 21$, amonabactin gene $a m o A$, and enterobactin receptor from $A$. hydrophila CECT $839^{\mathrm{T}}$ were used to query the publically available genomes. The nucleotide sequences were queried using blastn (version 2.2.30+) with the word size set of 9 to increase sensitivity and requiring $75 \%$ of the query to be present in the hit.

\section{Results}

\section{A. veronii (HM21) Produces a Siderophore and Utilizes Heme-containing Molecules as an Iron Source}

Our goal was to determine if the A. veronii leech-isolate, HM21, requires an iron utilization system for successfully colonizing the leech gut. The ability of HM21 to produce siderophores was revealed by streaking on agar containing chrome azurol S (CAS). When siderophores have a higher affinity for ferric iron than CAS, the siderophores remove $\mathrm{Fe}^{3+}$ from CAS leading to a dramatic color change from deep blue to orange or yellow. The presence of an orange halo around the colonies suggested that HM21 produces siderophores that have a greater affinity for $\mathrm{Fe}^{3+}$ than CAS (Figure 1A). This approach was used to screen for transposon mutants with altered siderophore production phenotypes. Mutants were generated in a spontaneous $\mathrm{Rf}^{\mathrm{R}}$ mutant of HM21, HM21R, using a miniTn5 (Graf, 1999a; Larsen et al., 2002; Maltz and Graf, 2011). A total of 1900 A. veronii miniTn 5 mutants were screened on CAS agar for changes in the iron sequestration phenotype. This screen bared two mutants with altered siderophore production phenotypes. Mutant S497 produced a brighter halo then the parent strain HM21R, indicative of an excessive siderophore productivity phenotype (Figures 1A,B), and mutant S-495 produced less siderophore than the parent strain (data not shown). The insertion site was 

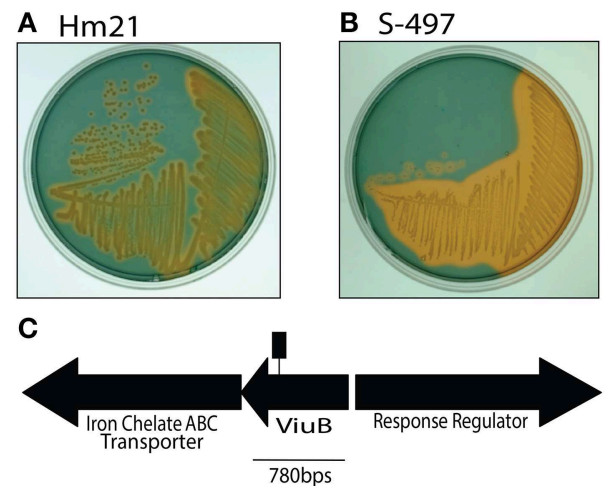

D

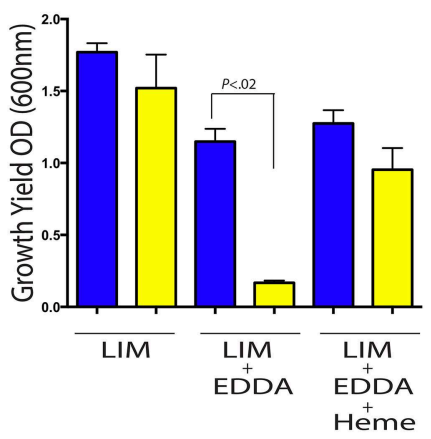

FIGURE 1 | Siderophore activity in $\boldsymbol{A}$. veronii. The siderophore production of the parent strain Hm21R (A) and the transposon mutant S-497 (B) were assessed using CAS agar. The iron-CAS complex changes color from blue to orange when iron is dissociated from CAS and thus can reveal the production of a siderophore. A portion of the siderophore locus from $A$. veronii, $\mathrm{Hm} 21$, is shown (C). The transposon insertion site is indicated by the square lollipop (C). The in vitro LIM growth yield of HM21R (blue) and S-497 (yellow) mutant was determined by measuring the $\mathrm{OD}_{600} 24 \mathrm{~h}$ after inoculation in LIM, LIM (150 $\mu \mathrm{M}$ EDDA) or LIM (150 $\mu \mathrm{M}$ EDDA and $50 \mu \mathrm{g} / \mathrm{ml}$ hemin) (D). The statistically significant difference between the parent strain and each mutant was performed using the Mann-Whitney test. This revealed HM21 possess a mechanism for utilizing iron from heme containing molecules.

identified by sequencing the flanking DNA using inverse PCR (Figure 1C). BLASTX searches of the NCBI database revealed that the deduced amino acid sequence of the inactivated gene in S-497 was $65 \%$ identical to ViuB (vibriobactin utilization protein) from $A$. hydrophila, suggesting that this mutant is unable to utilize iron bound to a siderophore since it cannot hydrolyze the ligand and release iron. In response, S-497 is iron starved and overproduces siderophores. BLASTX searches of the NCBI database revealed in S-495 the Tn inserted in the siderophore receptor. Like Vibrio anguillarum and other Gramnegative bacteria, the siderophore receptor in HM21 could be located within a siderophore biosynthetic operon, causing the polar effect of the Tn insertion to inactive multiple biosynthetic genes (Actis et al., 1986). For this reason we focused on S-497 in this study.

The $v i u B$ mutant was further characterized under iron limiting conditions by exploring in vitro phenotypes through measuring growth yields. In a LIM, HM21R, and S-497 reached a similar density $24 \mathrm{~h}$ after inoculation (Figure 1D). The effect of sequestering iron with $150 \mu \mathrm{M}$ of the iron chelator EDDA
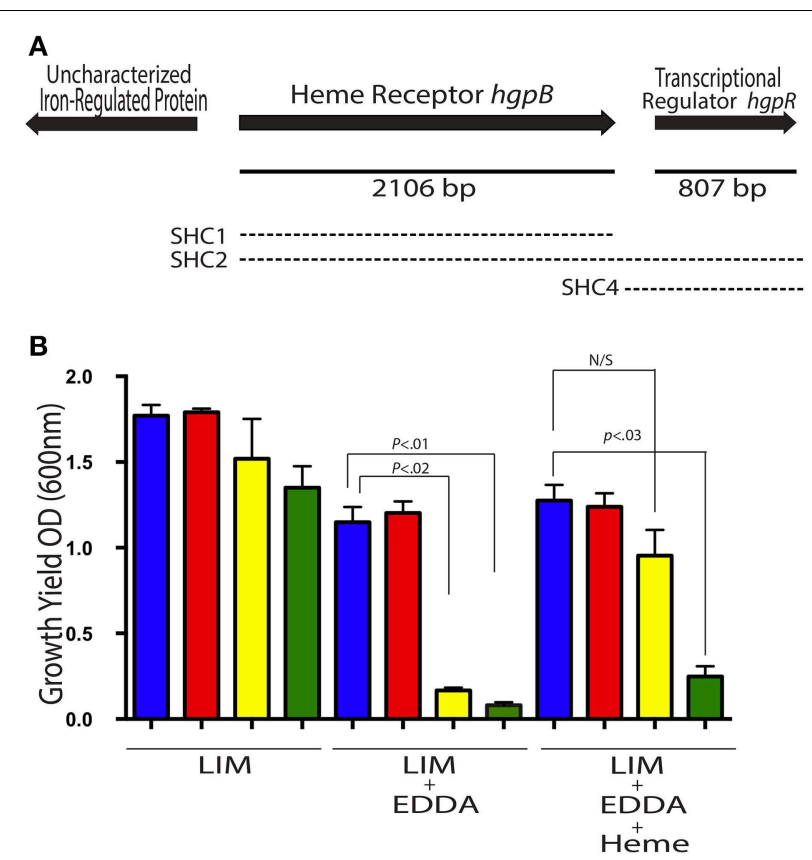

FIGURE 2 | $\boldsymbol{A}$. veronii possess gene for utilizing iron from heme. The heme receptor locus from HM21 is shown (A). The solid line indicates length of the gene. The three regions used for complementation with a Tn7 are represented by the dashed lines, the upper dashed line (SHC1), the middle dashed line (SHC2), and the bottom dashed line (SHC4). (B) The growth yield of Hm21R (blue); H-890 (red), the hgpB mutant; S-497 (yellow), the siderophore mutant; and $\mathrm{SH}-894$ (green), the double mutant was determined by measuring the $\mathrm{OD}_{600} 24 \mathrm{~h}$ after inoculation in LIM, LIM (150 $\mu \mathrm{M}$ EDDA), or LIM (150 $\mu \mathrm{M}$ EDDA and $50 \mu \mathrm{g} / \mathrm{ml}$ hemin). The statistically significant difference between the parent strain and each mutant was performed using a Mann-Whitney test. This revealed the requirement of the $h g p B$ for utilizing hemin as an iron source in the presence of EDDA.

revealed that the growth yield of S-497 was significantly lower than HM21R, showing the importance of siderophores for acquiring iron under these growth conditions. Interestingly, the addition of heme $(50 \mu \mathrm{M})$ restored the growth yield of S-497 to that of the parent strain, suggesting S-497 can utilize hemecontaining molecules in a siderophore-independent manner.

\section{HM21 Genome Contains a Heme Receptor}

Our next goal was to identify the genes in A. veronii HM21 that are important for utilizing heme-containing molecules. We first queried the genome of $A$. veronii for heme utilization genes, which revealed a heme receptor that has an $80 \%$ amino acid identity to $A$. hydrophila's putative outer-membrane heme receptor, $h g p B$. The corresponding open reading frame is 2106 bp long and is flanked by ORFs encoding an uncharacterized iron-regulated protein upstream and a transcriptional regulator downstream (Figure 2A).

Bioinformatic analyses provided further support for the role of the $h g p B$ homolog in heme utilization. A PDB (Protein databank) analysis revealed a significant similarity $\left(e\right.$-value $\left.1.5 \times 10^{-36}\right)$ to ShuU, the crystallized heme/hemoglobin outer membrane transporter from Shigella dysenteriae, which forms a beta barrel structure (Cobessi et al., 2010). InterProScan further supported 
this by revealing the presence of a signal sequences, TonBdependent receptor plug and a beta- barrel. SignalP analysis indicated the presence of a signal sequences with a cleavage site between residues 24 and 25 . This information supports the role of this protein as a putative heme receptor and in turn we name this gene $h g p B$.

We then generated mutants within the chromosome of $A$. veronii by recombining a fragment of DNA containing a portion of $h g p B$ fragmented by an antibiotic maker into HM21RS and S-497S yielding mutants with an interrupted hgpB (H-890, heme mutant) and a double mutant (SH-894, siderophore-heme double mutant). The interruption of $h g p B$ was verified by PCR and the expected band shift was observed in the mutants but not the parent strains (data not shown), verifying that the $\mathrm{Cm}^{\mathrm{R}}$ cassette interrupted $h g p B$.

In vitro phenotypes of heme utilization mutants were examined under iron limiting conditions by measuring growth yields and plating on LIM EDDA + heme plates (Figure 2B and Supplementary Figure 1). In LIM, HM21R, H-890, S-497, and $\mathrm{SH}-894$ reached a similar density $24 \mathrm{~h}$ after inoculation (Figure 2B). In LIM containing $150 \mu \mathrm{M}$ EDDA, HM21R and $\mathrm{H}-890$ had similar growth yields, suggesting that $h g p B$ is not essential for growth in the presence of EDDA and that ironsiderophore utilization is sufficient. As expected, the growth yield of SH-894 was significantly lower than HM21R when grown in LIM containing $150 \mu \mathrm{M}$ EDDA, showing the same phenotype as S-497. The addition of heme $(50 \mu \mathrm{M})$ did not restore growth of SH-894 to parent strain levels, indicating that $\mathrm{SH}-894$ lost the ability to utilize iron through both siderophores and heme utilization (Figure 2). These results confirmed $h g p B$ is required for utilization of iron bound to heme. When grown on LIM EDDA + heme plates similar results to the growth yield experiments in liquid media were obtained. HM21R, H-890, S497 grew similarly on the plate while $\mathrm{SH}-894$ did not grow on the plates indicating the loss of ability to utilize heme-containing molecules (Supplementary Figure 1).

\section{The Ability to Utilize Heme-containing Molecules is Important for Colonization of the Leech Crop}

Next we examined the ability of mutants to grow in blood as a control over a $72 \mathrm{~h}$ time course $(18,24,42$, and $72 \mathrm{~h}$ ) (Figure 3A). $18 \mathrm{~h}$ after inoculation, HM21, H-890, S-497, and SH-894 grew to similar levels. By $24 \mathrm{~h}, \mathrm{H}-890$ and SH-894 had a significantly lower $\mathrm{CFU} / \mathrm{mL}$ when compared to the parent strain, HM21 and S-497. These data suggest that at $24 \mathrm{~h}$ the heme receptor is more important for iron acquisition in blood than siderophores. By $42 \mathrm{~h}$ after inoculation, SH-894 had a growth defect when compared to the parent strain but for $\mathrm{H}-890$ growth is restored, suggesting that siderophores can compensate for the heme-utilization defect $42 \mathrm{~h}$ after inoculation in vitro. By $72 \mathrm{~h}$, the concentration of CFU decreased in all strains, analogous to a decrease observed during late stationary phase.

The ability of the mutants to colonize the digestive tract of $H$. verbana was monitored at $24 \mathrm{~h}$ (Figure 3B) by introducing the bacteria in a blood meal. H-890 and SH-894 colonized the leech to a significantly lower level then the parent strain and S-497 (Whitney test, $P=0.0159$ ) indicating that the ability to utilize
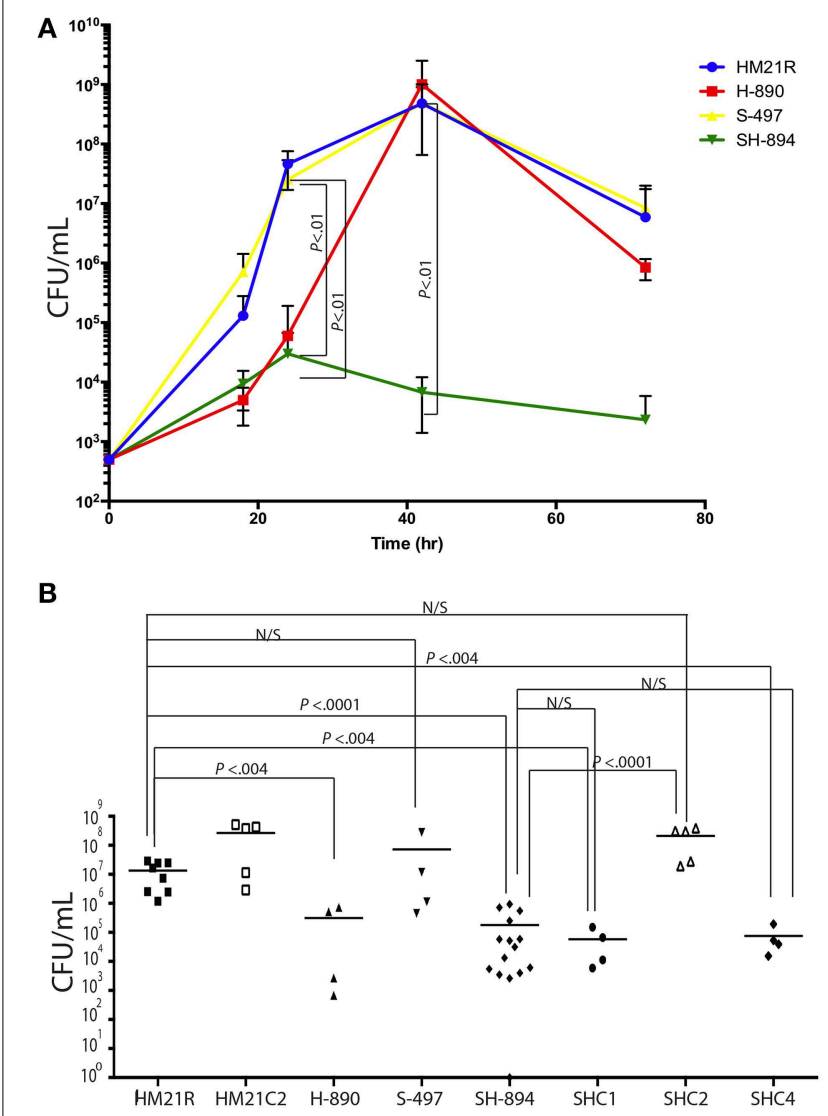

FIGURE 3 | In vitro and in vivo proliferation of iron utilization mutants. A time course of growth in blood of Hm21R (blue); $\mathrm{H}-890$ (red), the hgpB mutant; S-497 (yellow), the siderophore mutant; and SH-894 (green), the double mutant at $18,24,42$, and $72 \mathrm{~h}$ is shown (A). This revealed that in blood either viuB or hgpB suffice for growth. The symbols represent the average of 3 leech gut samples (A). Colonization of iron utilization mutants and complemented strains within the leech crop is shown (B). Each symbol represents the colonization level in one leech. The statistically significant difference between the parent strain and each mutant was performed using a Mann-Whitney test. Bonferroni corrections were preformed and the critical threshold is 0.007 . N/S, not significant.

heme containing molecules, rather than relying on siderophores for obtaining iron, is necessary for A. veronii to acquire iron inside the crop and successfully colonize the leech.

\section{Complementation of Heme Utilization Mutant SH-894}

As the goal of our investigation was to determine which iron utilization system was required for colonizing the leech digestive tract, we focused on complementing the $h g p B$ locus and evaluated its role in utilizing heme as an iron source and in the colonization of the leech in the mutant ( $\mathrm{SH}-894)$ with the inactivated $h g p B$ locus. $h g p B$ was introduced to $\mathrm{SH}-894$ on a Tn7, yielding SHC1 (Table 1). Complementation was initially assessed by growth curves in LIM, LIM containing $150 \mu \mathrm{M}$ EDDA, and LIM containing $150 \mu \mathrm{M}$ EDDA supplemented with heme $(50 \mu \mathrm{M})$. As expected, SHC1 grew to similar rates as the parent strain in LIM 
suggesting no general growth defect (data not shown). Since the complemented strain still retains the original loss of siderophore utilization, $150 \mu \mathrm{M}$ of EDDA interfered with the growth of SHC1 but not with the growth of HM21, which is consistent with above findings from S-497 (Siderophore mutant) (data not shown and Figure 1). The addition of heme relieved the growth inhibition of SHC1 but only after a very long lag phase (Supplementary Figure 2 ). These data link the $h g p B$ mutation to the heme utilization phenotype as $h g p B$ restored the ability to utilize heme in vitro when EDDA is present, however, the strain had a long lag phase suggesting a slow adaptation to a new source of iron. Leech colonization assays revealed that $\mathrm{SHC1}$ was unable to grow or colonize to equal levels as the parent strain (Figure 3B). These data suggest that complementing $\mathrm{SH}-894$ with $h g p B$ alone did not restore the ability of the mutant to colonize the leech gut.

One hundred and seventy-nine bp downstream of $h g p B$ is another open reading frame, ORF3, that is transcribed in the same direction and predicted to encode a transcriptional regulator (Figure 2A). Using ProDom, a comparison of the deduced amino acid sequence was done suggesting that the protein belongs to the LuxR family of regulators, possesses both the DNA-binding and autoinducer-binding regions (Corpet et al., 2000; Aziz et al., 2008) and 39.2\% of the amino acids were identical to the verified LuxR homolog from A. hydrophila, AhyR. Querying the HM21 genome with AhyR revealed the presence of two additional homologs. One of the other homologs has the greatest sequence identity to AhyR (91.2\%) and is found next to the LuxI homolog, which is the typical gene organization in Aeromonas species (Kirke et al., 2004).

We examined the role of ORF3, which encodes the regulator, and the intervening DNA region of $h g p B$, by constructing a Tn7 vector carrying both $h g p B$ and ORF3. This construct was introduced in the double mutant, $\mathrm{SH}-894$ yielding SHC2. In contrast to SHC1, SHC2 grew without a significant growth lag in LIM supplemented with EDDA and heme (Supplementary Figure 2). These data suggests that ORF3 alleviated the long lag phase. Based on the alleviation in the lag phase when growing on heme and the similarity of ORF3 to LuxR-type regulators, we propose to name this gene $h g p R$, for regulator. Complementation of the leech colonization phenotypes was assessed using SHC2 at $24 \mathrm{~h}$ (Figure 3B). The siderophore-heme receptor double mutant, SH894, grew to similar levels as the parent strain, $\mathrm{Hm} 21 \mathrm{R}$, when complemented with a $\operatorname{Tn} 7$ carrying both $h g p B$ and $h g p R$. This links the colonization defect to the heme utilization locus.

One explanation of these results is that the mutation in $h g p B$ could have caused a polar mutation, reducing or preventing the transcription of $h g p R$. RT-PCR was done to detect expression of $h g p B$ and $h g p R$ in strains HM21R, SH-894, SHC1, and SHC2 grown in LIM for $24 \mathrm{~h}$ with heme to determine whether there was a polar effect. The positive control transcript, rpoB, was detected in all strains (Data not shown). As expected, $h g p B$ transcripts were detected in HM21R, SHC1, and SHC2 but not in SH-894, suggesting that $h g p B$ was complemented in SHC1 and SHC2 (Supplementary Figure 3). RT-PCR of $h g p R$ revealed its transcript was detected in HM21R and SHC2 but not in SHCland SH-894 (Supplementary Figure 3). An alternative explanation is that untranslated regions, UTRs, of the mRNA were responsible. A third complemented strain was constructed that included the intergenic region up and downstream of $h g p B$, SHC3 (Supplementary Figure 4). These data show that the intergentic regions and $h g p B$ could not restore the colonization defect within the leech crop. While it is still possible that the UTR is larger than the intragenic regions, the data as a whole provide support for a polar effect of the $h g p B$ inactivation on $h g p R$.

We wanted to determine whether the observed defects were due directly to the downstream effect on $h g p R$. For this goal, we complemented SH-894 with $h g p R$ only, yielding SHC4. We then tested the ability of SHC4 to grown on LIM EDDA + heme plates (Supplementary Figure 1 EDDA). SHC4 was unable to grow on LIM EDDA + heme indicating that the heme utilization phenotype was not complemented. We also tested the ability of SHC4 to colonize the leech crop (Figure 3B). SHC4 was unable to colonize to similar levels as the parent strain. To investigate whether $h g p R$ was being expressed in SHC4 we did qRT-PCR on in vitro cultures (Figure 4). We took overnight cultures of HM21, H-890, SH-894, and SHC4 grown in LIM + HEME and extracted RNA. After reverse transcribing the mRNA into cDNA we determined the expression of $h g p B$ (Figure 4A) and $h g p R$ (Figure 4B) relative to the house keeping gene $r p o B$. As expected, the expression of $h g p B$ in $\mathrm{H}-890, \mathrm{SH}-894$ and $\mathrm{SHC} 4$ was significantly lower than in HM21 (Figure 4A). The expression of $h g p R$ in $\mathrm{H}-890$ and $\mathrm{SH}-894$ was significantly lower than in HM21 but as expected in SHC4 the expression of $h g p R$ was similar to HM21, indicating SHC4 had been complemented with $h g p R$ and this gene was being expressed. Together these data show that $h g p R$ alone is unable to restore the leech colonization defect and that $h g p B$ and $h g p R$ are both important for leech colonization.

\section{Restoration of Heme Utilization Phenotype Using Free Iron}

We wanted to test if there is a link between the inability to utilize iron from heme-containing molecules and the colonization phenotype (Figure 5). Leeches were fed blood meals containing either HM21 or SH-894 supplemented with EDDA $(150 \mu \mathrm{M})$ or ferric chloride $(160 \mu \mathrm{M})$. When inoculated into the blood meal containing EDDA, SH-894 growth did not change when compared to growth in blood suggesting that there are not sufficient amounts of free iron present in the blood meal or leech crop to allow the growth of $\mathrm{SH}-894$. When ferric chloride was added to the blood meal SH-894 grew to similar levels as the parent strain while in animals fed a normal blood meal SH-894 failed to establish itself. These results suggest there are insufficient amounts of free iron in the crop to support Aeromonas growth unless iron can be liberated from heme-containing molecules and that this accounts for the colonization defect of the $h g p B$ mutant in the leech crop.

\section{Presence of Iron Uptake Genes in Aeromonas species and Among A. veronii Strains}

The importance of iron utilization in this beneficial symbiosis and the role of iron as a virulence factor in other organisms led us to investigate the distribution of iron-uptake genes among 67 genomes representing 28 Aeromonas species (Table 2). This set of strains consists of isolates obtained from a wide range of samples 


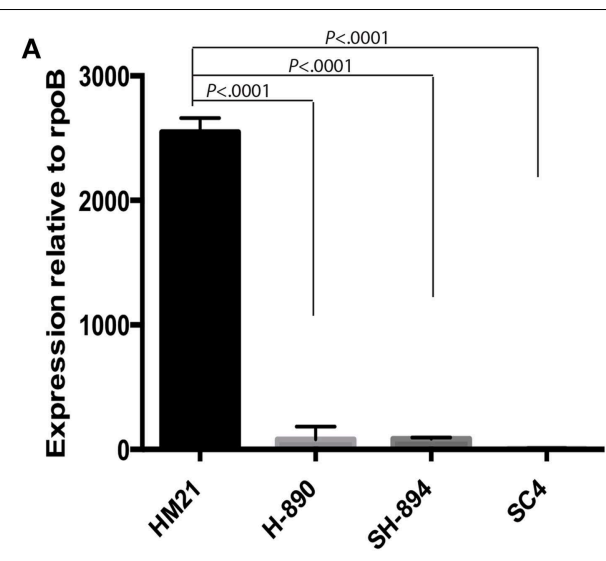

B

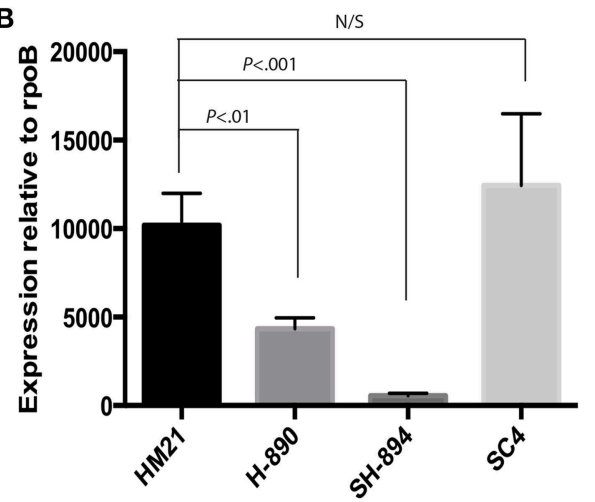

FIGURE 4 | QRT-PCR on hgpB mutants. Transcripts from cultures growth in an iron limiting medium with heme present was investigated for expression of $h g p B(\mathbf{A})$ and $h g p R(\mathbf{B})$ relative to $r p o B$. As expected the expression of $h g p B$ is significantly lower in both $h g p B$ mutants then $H M 21$, indicating that the gene was successfully knocked out (A). The expression of $h g p R$ is significantly lower in both $h g p B$ mutants when compared to HM21, revealing a possible polar mutation effecting transcription of $h g p R$ (B). Complementation with only $h g p R(\mathrm{SHC} 4$ ) did not restore expression of $h g p B$, providing further evidence for a polar mutation (A). The statistically significant difference was determined using $P<0.05$ Mann-Whitney test. Bonferroni corrections were preformed and the critical threshold is 0.016 . Relative expression was calculated using the $2^{-\Delta \mathrm{Ct}}$ method.

including clinical, veterinary and environmental. All genomes except $A$. simiae CIP $107798^{\mathrm{T}}$ contained the heme receptor, $h g p B$, indicating that the ability to obtain iron from heme is widespread among members of this genus. In contrast the distribution of $v i u B, 2,3$-dihydroxybenzonate AMP ligase, and amonabactin was not uniform. The 2,3-dihydroxybenzonate AMP ligase that is involved in the biosynthesis of enterobactin was present in all 11 A. veronii genomes but absent in all $4 A$. hydrophila and 2 A. caviae genomes. In contrast, all $A$. hydrophila and $A$. caviae encoded for amoA that is involved in the biosynthesis of amonabactin, while none of the $A$. veronii strains encoded for AmoA. The other iron utilization genes were more uniformly distributed. All genomes encoded a ferrous iron transport system. While siderophore transport permease, enterobactin receptor, ABC-type $\mathrm{Fe} 3+$ transport system, iron III dicitrate transport system and ferric hydroxamate $\mathrm{ABC}$ - transporters were present in the vast majority of the genomes. It is important to point out that the absence of a hit does not necessarily imply the absence of the gene. For example, the iron uptake regulator, Fur, was missing from $A$. sp. 159 this is probably due to low sequence similarity or an incomplete genome as this regulator would be predicted to be present in all of the genomes. These data indicate that heme utilization may be a molecular requirement for both pathogenic and beneficial relationships. 34 out of 67 strains have a similar $v i u B$ as HM21 indicating the importance of the ability to utilize iron from a siderophore, even when the bacteria did not posses the genes to produce their own siderophore.

\section{Discussion}

The primary goal of this study was to investigate the importance of iron-utilization by $A$. veronii in the leech symbiosis using molecular genetic approaches and leveraging access to the genomes of Aeromonads. Because relatively little is known about the genetic requirements for iron-uptake in Aeromonas, we used a bioinformatic approach to gain insight into the prevalence of iron utilization genes in this genus (Najimi et al., 2008; Funahashi et al., 2013). Our data reveals that the ability to obtain hemebound iron is essential for A. veronii strain HM21 to successfully colonize the leech crop and that $h g p B$ is widespread among Aeromonads.

Focusing initially on siderophores, we were able to show that HM21 synthesizes siderophores and that siderophore utilization is not required for colonizing the leech digestive tract. Similarly, Photorhabdus luminescens was shown not to require siderophores to colonize its symbiotic nematode host, Heterorhabditis bacteriophora, nor for virulence in the insect hosts (Ciche et al., 2003). This is in contrast to the $V$. fischeri symbiosis where the production of siderophores are essential for colonization of the light organ within the Hawaiian bobtail squid, Euprymna scolopes (Graf and Ruby, 2000). In the shipworm symbiosis (another marine system), siderophore biosynthetic genes were found in the genome of endosymbiont Teredinibacter turnerae and the siderophore was detected in the shipworm extracts, suggesting that its expression plays a role in this symbiosis (Han et al., 2013). There does not appear to be a strict requirement for siderophore-dependent iron utilization during colonization of animal hosts within beneficial associations, suggesting that alternative mechanism are employed.

In this study, we identified a second distinct iron-utilization mechanism in $A$. veronii strain HM21 involving heme. A potential heme utilization gene, $h g p B$ was detected in the HM21 genome. $h g p B$ mutants were constructed to characterize the role of $h g p B$ in iron uptake from heme and the colonization of the leech. The loss of the ability to acquire iron bound to heme was verified in the double mutant (the $h g p B$ and $v i u B$ mutant, SH894) when grown in LIM with EDDA + heme, which supported the importance of $h g p B$ in utilization of iron bond to heme. Bacterial growth data from a time course performed in blood indicated that either iron acquired by a siderophore or heme receptor is sufficient for $A$. veronii to proliferate in a blood environment. The double mutant grew to significantly lower concentrations in blood when compared to the parent strain and the other mutants. While some bacteria, including HM21, have 


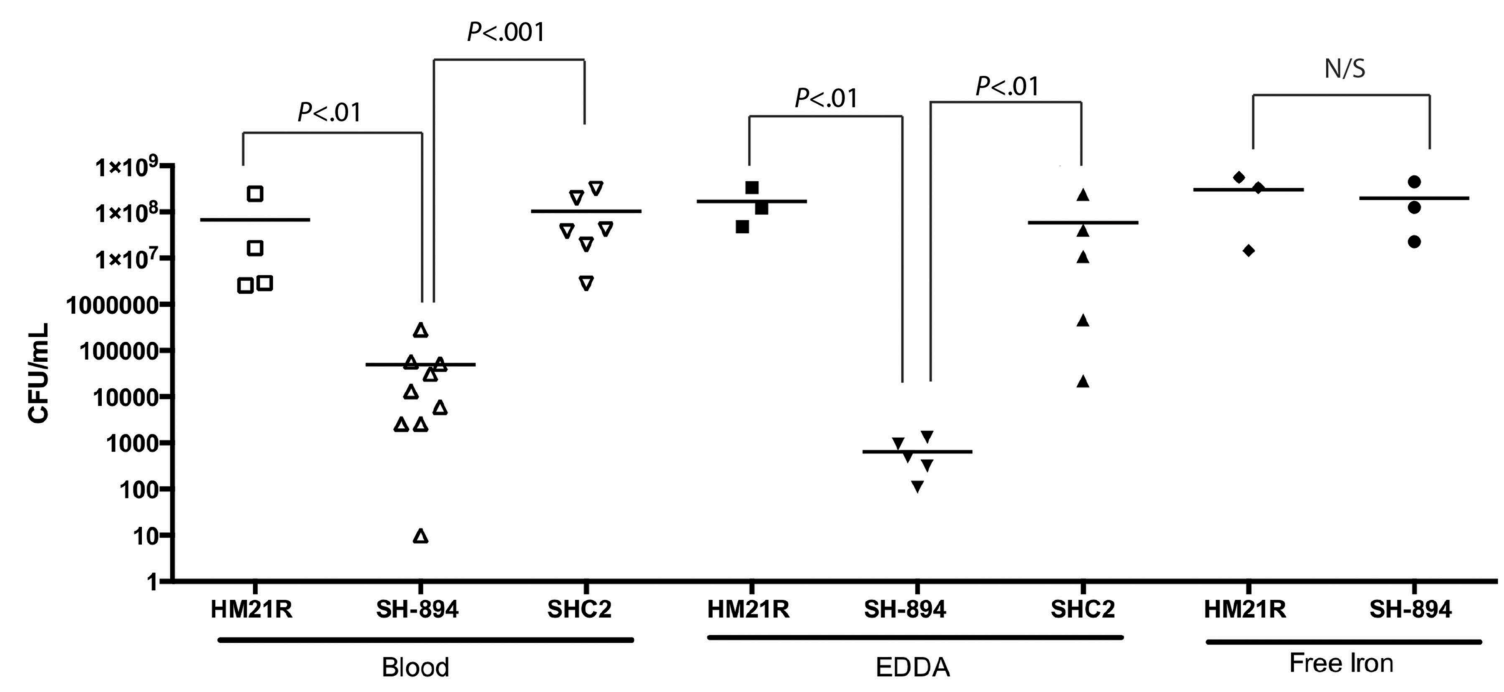

FIGURE 5 | Restoration of double mutant (SH-894) using free iron. The leech crop colonization of the double mutant using a chemically manipulated blood meal is shown. One hundred and fifty micrometer EDDA was added to the blood meal along with strains to show minimal amounts of a

non-protein-bound iron (free iron) with in the leech crop. SH-894 cannot

colonize the leech crop. When $160 \mu \mathrm{M}$ of ferric chloride (free iron) is added to the blood meal the colonization defect of the double mutant was restored, further linking the inability to obtain iron within the leech crop. Each symbol represents the colonization level in one leech. The statistically significant difference between the parent strain and each mutant was performed using a Mann-Whitney test. Bonferroni corrections were preformed and the critical threshold is 0.025 . other iron acquisition system, including ferrous and ferric iron receptors (Table 2), this data suggests that for growth in blood these other iron utilization systems are not sufficient for HM21 to proliferate.

Leech colonization assays using the $h g p B$ mutants revealed that the ability to acquire iron bound to heme is essential for $A$. veronii to colonize the leech crop. These data also suggests that iron potentially bound to transferrin is not present at sufficient levels, cannot be utilized by $A$. veronii or that other bacteria such as the abundant $M$. hirudinis outcompete $A$. veronii for transferrin. Utilization of iron bond to heme necessitates access to hemoglobin that is contained within the erythrocytes. While early studies reported that the erythrocytes remain physically intact for many months inside the crop of the leech and do not fully lyse until they enter the intestinum (Graf, 1999b), we have since demonstrated that the ability of $A$. veronii to lyse erythrocytes in the leech crop is essential for initial colonization (Maltz and Graf, 2011). The ability to access heme-bound iron provides further mechanistic evidence that at least a portion of the erythrocytes are lysed or are being permeabilized by $A$. veronii in the leech crop. Whether this aids the leech in digestion of the consumed blood meal or competes with the host for nutrients remains to be evaluated.

Complementation of the $h g p B$ mutants indicated that $h g p B$ alone was not sufficient to restore the leech colonization phenotype and revealed the requirement for both $h g p B$ and $h g p R$ to be present in order to restore the colonization ability of the double mutant. RT-PCR and qRT-PCR data revealed a possible polar effect of the $h g p B$ mutation resulting in a reduced expression of $h g p R$. Although the two genes are separated by $336 \mathrm{bp}$, the insertion of a large antibiotic cassette insertion could cause a frameshift downstream. Another possibility is that the fragment of $h g p B$ cloned for complementation (SCH1) is missing a critical $3^{\prime}$ UTR element that is needed for transcript stability. This is unlikely since SHC3 ( $h g p B+$ up and downstream intergenic region) did not complement the leech defect. Our data suggest that $h g p B$ and $h g p R$ are important for iron utilization bound to heme and which in turn is important for leech colonization. Future studies will investigate the role the regulator $(h g p R)$ plays on $h g p B$ and possibly other genes by making clean mutations in this heme utilization region.

While heme utilization has been mostly characterized in pathogenic associations, in two other beneficial symbioses, heme utilization has been shown to be important. In the Tsetse fly symbiont, Sodalis glossinidius analysis revealed that a heme receptor is upregulated inside the host digestive tract and that this heme receptor is important for colonization (Hrusa et al., 2015). As this is also a blood-feeding host and the symbiont can reside inside the digestive tract, which is an analogous habitat to the leech. However, in the V. fischeri-E. scolopes symbiosis where siderophores are required for symbiotic competence, a heme uptake cluster is also important for colonization for the light organ (Septer et al., 2011). In this case it was proposed that blebs of epithelial cells that might contain heme enter the light organ space and could serve as the source of iron.

The analysis of the Aeromonas genomes for iron utilization genes revealed that most Aeromonas strains contain a wide range of iron utilization genes. Interesting, the heme receptor is present in all but one of the genomes analyzed even though only A. hydrophila, A. jandaei, and A. veronii strains have been isolated from leeches (Silver and Graf, 2009; Colston et al., 2014). These data suggests a role for the heme receptor in 
TABLE 2 | Nucleotide percentage identity to iron uptake genes in Aeromonas species and among A. veronii strains.

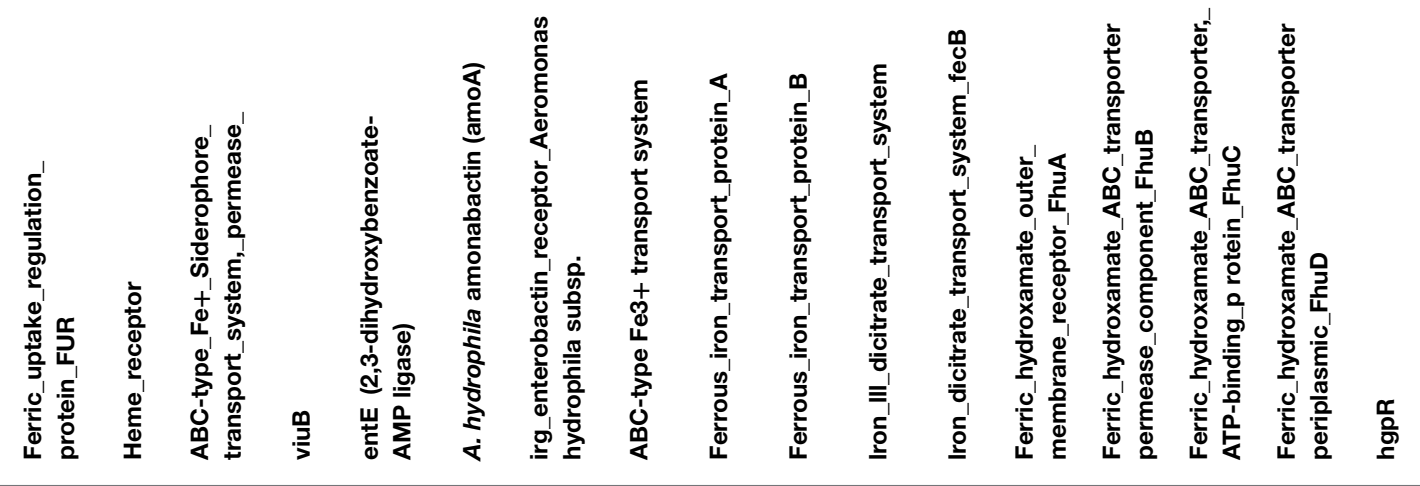

\begin{tabular}{|c|c|c|c|c|c|c|c|c|c|c|c|c|c|c|c|c|c|}
\hline A_allosaccharophila_BVH88 & 98.1 & 96.9 & 92.5 & 94.4 & & & 81.2 & 94.2 & 93.8 & 97.7 & 97.4 & 97.4 & 95.7 & 94.6 & 95.4 & 95.7 & \\
\hline A_allosaccharophila_CECT419 & 99.1 & 94.5 & 93.5 & 95.7 & & & 85.1 & 96.2 & 100 & 97.1 & 97 & 96.3 & 90.7 & 93.5 & 96.2 & 95.2 & \\
\hline A_aquariorum_AAKI & 91.8 & 82 & 79.8 & 75.3 & 78.8 & 90.7 & 91.2 & 80.3 & 88.9 & 88.5 & 88.9 & 79.7 & 88.7 & 86.3 & 91.8 & 83.6 & \\
\hline A_aquariorum_CECT7289T & 91.5 & 82 & 79.3 & & & 90.8 & 90.9 & 79.9 & 88.9 & 88.4 & 88.9 & 80.3 & 88.5 & 86.4 & 91.5 & 83.9 & 75.4 \\
\hline A_austrailiensis_CECT8023T & 97.4 & 92.3 & 94.7 & 95.9 & 94.74 & & 82.9 & 94.9 & 90.8 & 91.5 & 95.9 & 95 & & 83.6 & 77.8 & & \\
\hline A_bestarium_CECT4227T & 91.1 & 82.5 & 79.2 & & 76.78 & 84.5 & 92.9 & 79.6 & 87.2 & 87.2 & 80.6 & 78.3 & 88.4 & 86.4 & 90.1 & 84.4 & \\
\hline A_bivalvium_CECT7113T & 87.9 & 82 & 79.2 & & & 87.8 & 86.5 & 80.4 & 87.5 & 84.7 & 95.1 & 77.9 & 86.1 & 84.9 & 88.5 & 82.3 & \\
\hline A caviae Ae398 & 91.3 & 83 & 77.8 & & 78.14 & 89.7 & & 79.5 & 85.5 & 82.5 & 90.4 & 78.5 & 84.8 & 84.3 & 89.9 & 78.6 & \\
\hline A_caviae_CECT838T & 90.9 & 83 & 78 & & 77.78 & 89.5 & & 79.4 & 85 & 82.6 & 90.4 & 78.4 & 84.8 & 84.3 & 89.9 & 78.7 & \\
\hline A_diversa_CECT4254T & 87.7 & 75.5 & 79.8 & & 82.5 & 82.3 & 89.6 & 78 & 79.7 & 78.5 & 93.2 & & & & & & \\
\hline A_encheleia_CECT4342T & 91.2 & 83.7 & 78.6 & & 90 & 81.3 & 78.8 & 79.7 & 87.2 & 84.1 & 94.3 & 78 & 85.2 & 82.5 & 86 & 81.5 & \\
\hline A_enteropelogenes_1999 & 90.4 & 87.3 & 88.5 & 79.5 & 83.32 & & 83.5 & 85.2 & 88.9 & 87 & 87.8 & 81.6 & 88.1 & 85.7 & 90.7 & 86.3 & \\
\hline A_enteropelogenes_CECT448 & 90.7 & 87 & 87 & 79.6 & 83.56 & & 83.5 & 86.2 & 88.9 & 86.3 & 88.1 & 81.8 & 88 & 85.1 & 89 & 86.3 & \\
\hline A_eucrenophila_CECT4224T & 90.7 & 82.9 & 84.2 & & 86.08 & 84.1 & 78.8 & 80.6 & 87.7 & 82.9 & 87 & 77.8 & 85.4 & 83.8 & 88.6 & 80.3 & \\
\hline A_fluvialis_LMG24681T & 94.1 & 93.5 & & & & & & & 91.6 & 93.8 & 85.5 & & 92 & 93.4 & 96.9 & 93.3 & \\
\hline A_hydrophila_CECT839T & 91.9 & 81.4 & 79.1 & & & 92.4 & 100 & 79.8 & 88.9 & 88.9 & 90.9 & 80 & 89.4 & 86.9 & 91.9 & 84.2 & \\
\hline AJiydrophila_CIP107985 & 91.9 & 81.6 & 78.7 & & 81.69 & 92.9 & 98.4 & 80.7 & 88.9 & 88.7 & 86.2 & 79.6 & 88.7 & 85.7 & 90.6 & 83.2 & \\
\hline A_hydrophila_SNUFPCA8 & 91.5 & 81.6 & 78.9 & & 77.38 & 92.8 & 97.6 & 79.9 & 89.8 & 88.8 & 94.3 & 79.5 & 89.4 & 86.3 & 91.7 & 84 & \\
\hline A_hydrophila_ML09119 & 91.7 & 81.4 & 78.8 & & 76.42 & 92.7 & 98.1 & 80.7 & 88.5 & 88.5 & 90.9 & 79.7 & 88.9 & 85.7 & 92 & 84.4 & \\
\hline A_dhakensis_014 & 91.5 & 81.9 & 79.3 & & & 91.5 & 91.1 & 80.6 & 89.8 & 88.5 & 88.9 & 79.3 & 88.8 & 86.2 & 90.9 & 83.2 & 75.8 \\
\hline A_dhakensis_116 & 91.5 & 81.9 & 79.3 & & & 91.5 & 91.1 & 80.6 & 89.8 & 88.5 & 88.9 & 79.3 & 88.8 & 86.2 & 90.9 & 83.2 & 75.8 \\
\hline A_hydrophila_145 & 92 & 81.7 & 79.4 & & & 91.2 & 91.3 & 79.2 & 87.6 & 88.6 & 88.9 & 79.4 & 88.6 & 85.9 & 91.5 & 84 & 75.7 \\
\hline A_dhakensis_173 & 92 & 82.1 & 79.4 & 751 & & 92.2 & 91 & 79.3 & 88.9 & 88.1 & 88.9 & 79.8 & 88.8 & 86.8 & 91.5 & 83.7 & \\
\hline A_dhakensis_187 & 92 & 82.4 & 79 & 75.7 & 76.42 & 91.3 & 91.2 & 79.6 & 88.5 & 88.5 & 88.9 & 79.5 & 86.5 & 86.1 & 91.6 & 84.3 & 76.6 \\
\hline A_hydrophila_226 & 91.5 & 81.8 & 78.5 & & & 93.2 & 97.9 & 79.9 & 88.1 & 88.8 & 90.9 & 79.6 & 89.1 & 86.6 & 91.9 & 83.1 & \\
\hline A_dhakensis_259 & 92 & 82 & 79.4 & 75.5 & 76.06 & 91.3 & 91.1 & 79.3 & 88.5 & 88.5 & 92.9 & 79.9 & 88.7 & 86.4 & 91.5 & 83.4 & 75.7 \\
\hline A_dhakensis_277 & 92 & 81.8 & 79.5 & 75 & & 91.4 & 91.2 & 79.6 & 88.9 & 88.3 & 88.9 & 79.3 & 88.6 & 86.1 & 91.3 & 83.8 & 76.1 \\
\hline A_hydrophila_289 & 91.7 & 81.7 & 79.1 & & 75 & 93.7 & 98.2 & 79.5 & 88.9 & 88.9 & 94.3 & 80.1 & 89.1 & 86.1 & 92 & 83.5 & \\
\hline A_dhakensis_CIP107500 & 92 & 82.1 & 78.4 & 75.3 & 76.81 & 91.3 & 91.4 & 80.9 & 87.6 & 88.7 & 88.9 & 80 & 86.4 & 86.4 & 91.9 & 84.1 & 75.6 \\
\hline A_hydrophila_NFI & 91.7 & 81.5 & 79.4 & & & 93.7 & 98.1 & 80.4 & 88.9 & 88.9 & 94.3 & 80.1 & 89.1 & 88 & 92.2 & 83 & \\
\hline A_hydrophila_NF2 & 91.5 & 81.7 & 79 & & & 92.6 & 98.2 & 80 & 88.9 & 89.1 & 88.6 & 79.3 & 89.1 & 86.8 & 91.3 & 84.5 & \\
\hline A_hydrophila_SSU & 92 & 81.9 & 79.2 & 75.5 & 75.83 & 91.1 & 91.1 & 80.4 & 88.1 & 88.2 & 88.9 & 80 & 88.7 & 86.3 & 92 & 82.8 & 75.8 \\
\hline A_hydrophila_AH4 & 90.5 & 82.7 & 79 & & & 92.6 & 91.5 & 79.5 & 87.2 & 87.3 & 80.7 & 77.9 & 88.1 & 87.1 & 87.2 & 84.6 & \\
\hline AJandaei_CECT4228T & 92.9 & 89.7 & 95 & 84.4 & 93.89 & & 82.4 & 94.8 & 93.4 & 88.6 & 96.8 & 89.8 & & 93 & 77.9 & & 77.2 \\
\hline A_media_CECT4232T & 91.4 & 82.9 & 78.7 & & 76.13 & 88 & 87.2 & 79.7 & 86.7 & 82.9 & 92.7 & 78.1 & 86.1 & 84.1 & 87.9 & 80.4 & \\
\hline A_media_WS.42948 & 91.4 & 84.2 & 78.5 & & & 88.1 & & 79.7 & 86.7 & 82.9 & 96.9 & 78.4 & 86.8 & 84.2 & 89.5 & 80.8 & \\
\hline A_mollusconjm_CIP108876T & 87 & 77.7 & 79.4 & & & 88.8 & 82.4 & 78.6 & 79.8 & 80.9 & 90.2 & 75.4 & 83.6 & 77 & 87.2 & & \\
\hline A_piscicola_LMG24783T & 92 & 83.1 & 79.6 & & 77.83 & 85.4 & 91.8 & 79.1 & 87.2 & 87.3 & 80.7 & 78.5 & 88.1 & 87 & 89.3 & 82.9 & 77 \\
\hline A_popoffii_CIP105493T & 89.7 & 81.3 & 79.6 & & 76.19 & 83.8 & 84 & 79.6 & 91.6 & 88.6 & 80.2 & 85.9 & & 90.1 & 83.9 & & 78 \\
\hline A_rivuli_DSM22539T & 88.1 & 78.4 & 79.3 & 82.6 & 91.23 & 80.5 & 82 & 78.4 & 80.6 & 81.3 & 80.6 & 78.6 & 84.8 & & 80.3 & & \\
\hline
\end{tabular}




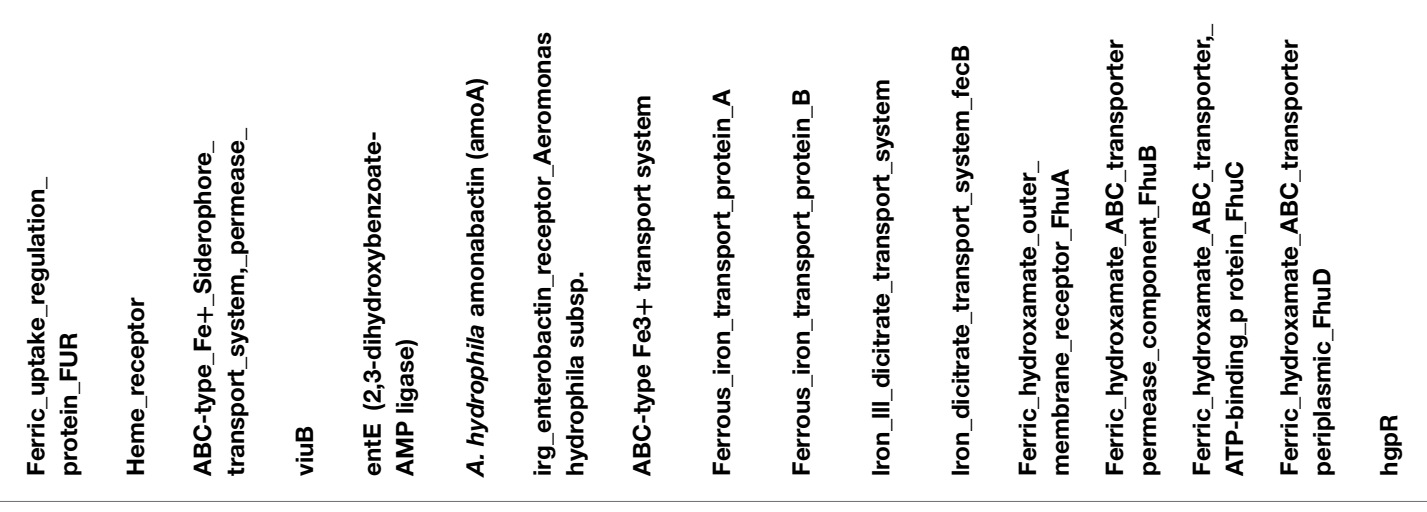

A_salmonicida_01B526

A_salmonicida_34

A_salmonicida_A449

A salmonicida $\mathrm{A503}$

A_salmonicida_CIP103209T

A_sanarelli_LMG24682T

A_sch u berti i_CECT4240T

A_simiae_CIP107798T

A_sobria_CECT4245T

A_sp_159

A_sp_MDS8

A_taiwanensis_LMG24683T

A_tecta_CECT7082T

A_trota_CECT4255T

A_veronii_AER28

A_veronii_AER39

A_veronii_AER397

A_veronii_AMC34

A_veronii_AIVIC35

A_veronii_8565

A_veronii_CECT4257T

A_veronii_Hm21

A_veronii_LMG13067

A_ichthiosmia_CECT4486

A_culicicola_CIP107763

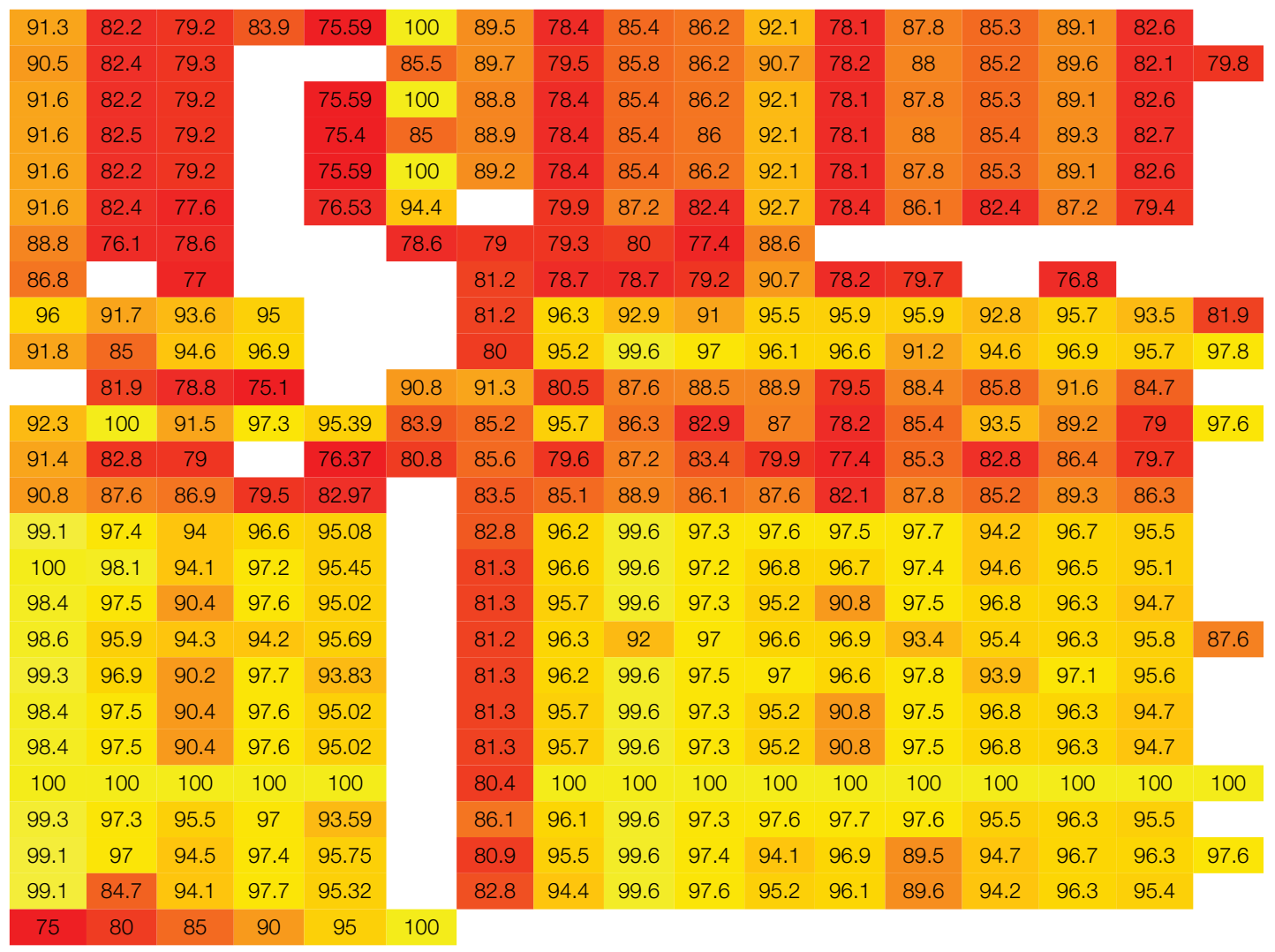

Nucleotide percentage identity. The redder the color the closer to $100 \%$ identity.

other habitats, including Aeromonas infections in humans, fish and amphibians. The heme receptor has also been shown to be dispersed in other species of bacteria with a wide host range, for example the Vibrios i.e.: Vibrio. anguillarum (a fish pathogen), $V$. cholerae (human pathogen), $V$. fischeri (beneficial symbiont) $V$. mimicus (human pathogen), and $V$. vulnificus (human pathogen) (O’Malley et al., 1999; Mouriño et al., 2005; Runyen-Janecky, 2013). Like Aeromonads, Vibrios can be found in different states, environmental, pathogenic, and symbiotic, indicating a role for the heme receptor in multiple habitants in multiple genera of bacteria.

Coexistence with a host requires a precise balance, allowing bacterial growth while preventing overgrowth. In animals with specialized symbiotic organs this can be achieved by controlling the release of nutrients, but in a digestive tract the control mechanisms probably require additional layers as the ingested food provides nutrients to both host and microbes. One such mechanism can be the restriction of free iron. There are additional requirements a microbe must posses to overcome physical, cellular, and molecular barriers presented by the host. As scientists investigate these bacterial interactions, it is becoming clearer that a number of these molecular requirements for microorganisms to colonize animals are similar between pathogenic and mutualistic associations, despite the different outcomes (Hentschel et al., 2000; Ochman et al., 2010). Iron is a nutritional requirement for most bacteria. Inside a host, protein 
binding sequesters iron. Therefore, for bacteria to overcome this barrier within a host they must acquire iron bound to host proteins. In a pathogenic state, it has been shown that bacteria require iron not only as a nutritional source but can also sometimes sense iron limitation with a host environment and release bacterial toxins or virulence factors (Litwin and Calderwood, 1993). Examples of iron-regulated virulence factors include; Shiga toxin (Shigella dysenteriae Type I), Exotoxin A (Pseudomonas aeruginosa), Diphtheria toxin (C. diphtheria) and SLT-I (E. coli) (Litwin and Calderwood, 1993). Our findings suggest, that within this mutualistic relationship, a microbe with a nutritional requirement for iron must posses a high-affinity iron utilization system to proliferate in the leech crop. These data indicate the importance of utilizing iron bond to heme for A. veronii in the colonization of the leech gut. We also show within the Aeromonas genus heme utilization is not limited to mutualistic associations since the presence of $h g p B$ was found

\section{References}

Actis, L. A., Fish, W., Crosa, J. H., Kellerman, K., Ellenberger, S. R., Hauser, F. M., et al. (1986). Characterization of anguibactin, a novel siderophore from Vibrio anguillarum 775(pJM1). J. Bacteriol. 167, 57-65.

Aziz, R. K., Bartels, D., Best, A. A., DeJongh, M., Disz, T., Edwards, R. A., et al. (2008). The RAST Server: rapid annotations using subsystems technology. BMC Genomics 9:75. doi: 10.1186/1471-2164-9-75

Barghouthi, S., Payne, S. M., Arceneaux, J. E., and Byers, B. R. (1991). Cloning, mutagenesis, and nucleotide sequence of a siderophore biosynthetic gene (amoA) from Aeromonas hydrophila. J. Bacteriol. 173, 5121-5128.

Barghouthi, S., Young, R., Arceneaux, J. E., and Byers, B. R. (1989b). Physiological control of amonabactin biosynthesis in Aeromonas hydrophila. Biol. Met. 2, 155-160. doi: 10.1007/BF01142554

Barghouthi, S., Young, R., Olson, M. O., Arceneaux, J. E., Clem, L. W., and Byers, B. R. (1989a). Amonabactin, a novel tryptophan- or phenylalanine-containing phenolate siderophore in Aeromonas hydrophila. J. Bacteriol. 171, 1811-1816.

Boccazzi, P., Zhang, J. K., and Metcalf, W. W. (2000). Generation of dominant selectable markers for resistance to pseudomonic acid by cloning and mutagenesis of the ileS gene from the archaeon Methanosarcina barkeri fusaro. J. Bacteriol. 182, 2611-2618. doi: 10.1128/JB.182.9.2611-2618.2000

Bomar, L., Stephens, W. Z., Nelson, M. C., Velle, K., Guillemin, K., and Graf, J. (2013). Draft genome sequence of Aeromonas veronii $\mathrm{Hm} 21$, a symbiotic isolate from the medicinal leech digestive tract. Genome Announc. 1:e00800-13. doi: 10.1128/genomeA.00800-13

Braschler, T. R., Merino, S., Tomas, J. M., and Graf, J. (2003). Complement resistance is essential for colonization of the digestive tract of Hirudo medicinalis by Aeromonas strains. Appl. Environ. Microbiol. 69, 4268-4271. doi: 10.1128/AEM.69.7.4268-4271.2003

Butterton, J. R., and Calderwood, S. B. (1994). Identification, cloning, and sequencing of a gene required for ferric vibriobactin utilization by Vibrio cholerae. J. Bacteriol. 176, 5631-5638.

Byers, B. R., Massad, G., Barghouthi, S., and Arceneaux, J. E. (1991). Iron acquisition and virulence in the motile aeromonads: siderophore-dependent and -independent systems. Experientia 47, 416-418.

Choi, K. H., Gaynor, J. B., White, K. G., Lopez, C., Bosio, C. M., KarkhoffSchweizer, R. R., et al. (2005). A Tn7-based broad-range bacterial cloning and expression system. Nat. Methods 2, 443-448. doi: 10.1038/nmeth765

Ciche, T. A., Blackburn, M., Carney, J. R., and Ensign, J. C. (2003). Photobactin: a catechol siderophore produced by Photorhabdus luminescens, an entomopathogen mutually associated with Heterorhabditis bacteriophora NC1 nematodes. Appl. Environ. Microbiol. 69, 4706-4713. doi: 10.1128/AEM.69.8.4706-4713.2003

Cobessi, D., Meksem, A., and Brillet, K. (2010). Structure of the heme/hemoglobin outer membrane receptor ShuA from Shigella dysenteriae: heme binding by an induced fit mechanism. Proteins 78, 286-294. doi: 10.1002/prot.22539 in both clinical and environmental isolates, further confirming the interesting parallelism between pathogenic and mutualistic relationships.

\section{Acknowledgments}

We would like to thank Hannah Monahan for her help with the EDDA assays and Amy Horneman, Mike Janda, Herbert Schweizer, and Martin Altwegg for strains. This research was funded by NSF Career Award MCB 0448052 and NIH RO1 GM095390 to JG.

\section{Supplementary Material}

The Supplementary Material for this article can be found online at: http://journal.frontiersin.org/article/10.3389/fmicb. 2015.00763

Colston, S. M., Fullmer, M. S., Beka, L., Lamy, B., Gogarten, J. P., and Graf, J. (2014). Bioinformatic genome comparisons for taxonomic and phylogenetic assignments using aeromonas as a test case. mBio 5:e02136-14. doi: $10.1128 / \mathrm{mBio} .02136-14$

Corpet, F., Servant, F., Gouzy, J., and Kahn, D. (2000). ProDom and ProDomCG: tools for protein domain analysis and whole genome comparisons. Nucleic Acids Res. 28, 267-269. doi: 10.1093/nar/28.1.267

Cox, C. (1994). Deferration of laboratory media and assays for ferric and ferrous ion. Methods Enzymol. 235, 315-329. doi: 10.1016/0076-6879(94) 35150-3

Crosa, J. H. (1989). Genetics and molecular biology of siderophore-mediated iron transport in bacteria. Microbiol. Rev. 53, 517-530.

Crosa, J. H., and Walsh, C. T. (2002). Genetics and assembly line enzymology of siderophore biosynthesis in bacteria. Microbiol. Mol. Biol. Rev. 66, 223-249. doi: 10.1128/MMBR.66.2.223-249.2002

de Lorenzo, V., and Timmis, K. N. (1994). Analysis and construction of stable phenotypes in gram-negative bacteria with Tn5- and Tn10derived minitransposons. Methods Enzymol. 235, 386-405. doi: 10.1016/00766879(94)35157-0

Falkow, S. (2004). Molecular Koch's postulates applied to bacterial pathogenicity [mdash] a personal recollection 15 years later. Nat. Rev. Microbiol. 2, 67-72. doi: $10.1038 /$ nrmicro799

Funahashi, T., Tanabe, T., Miyamoto, K., Tsujibo, H., Maki, J., and Yamamoto, S. (2013). Characterization of a gene encoding the outer membrane receptor for ferric enterobactin in Aeromonas hydrophila ATCC 7966. Biosci. Biotechnol. Biochem. 77, 353-360. doi: 10.1271/bbb.120774

Graf, J. (1999a). Molecular requirements for the colonization of Hirudo medicinalis by Aeromonas veronii. Mol. Basis Symbio. 41, 291-303. doi: 10.1007/3-54028221-1_14

Graf, J. (1999b). Symbiosis of Aeromonas veronii biovar sobria and Hirudo medicinalis, the medicinal leech: a novel model for digestive tract associations. Infect. Immun. 67, 1-7.

Graf, J. (2006). Molecular requirements for the colonization of Hirudo medicinalis by Aeromonas veronii. Prog. Mol. Subcell. Biol. 41, 291-303. doi: 10.1007/3-54028221-1_14

Graf, J., and Ruby, E. G. (2000). Novel effects of a transposon insertion in the Vibrio fischeri glnD gene: defects in iron uptake and symbiotic persistence in addition to nitrogen utilization. Mol. Microbiol. 37, 168-179. doi: 10.1046/j.13652958.2000.01984.x

Han, A. W., Sandy, M., Fishman, B., Trindade-Silva, A. E., Soares, C. A. G., Distel, D. L., et al. (2013). Turnerbactin, a novel triscatecholate siderophore from the shipworm endosymbiont Teredinibacter turnerae T7901. PLoS ONE 8:e76151. doi: 10.1371/journal.pone.0076151

Hentschel, U., Steinert, M., and Hacker, J. (2000). Common molecular mechanisms of symbiosis and pathogenesis. Trends Microbiol. 8, 226-231. doi: 10.1016/S0966-842X(00)01758-3 
Hrusa, G., Farmer, W., Weiss, B. L., Applebaum, T., Roma, J., Szeto, L., et al. (2015). TonB-dependent heme iron acquisition in the tsetse fly symbiont Sodalis glossinidius. Appl. Environ. Microbiol. 81, 2900-2909. doi: 10.1128/AEM. 04166-14

Indergand, S., and Graf, J. (2000). Ingested blood contributes to the specificity of the symbiosis of Aeromonas veronii biovar sobria and Hirudo medicinalis, the medicinal leech. Appl. Environ. Microbiol. 66, 4735-4741. doi: 10.1128/AEM.66.11.4735-4741.2000

Janda, J. M., and Abbott, S. L. (1998). Evolving concepts regarding the genus Aeromonas: an expanding panorama of species, disease presentations, and unanswered questions. Clin. Infect. Dis. 27, 332-344. doi: 10.1086/514652

Janda, J. M., and Abbott, S. L. (2010). The genus Aeromonas: taxonomy, pathogenicity, and infection. Clin. Microbiol. Rev. 23, 35-73. doi: 10.1128/CMR.00039-09

Janda, J. M., Reitano, M., and Bottone, E. J. (1984). Biotyping of Aeromonas isolates as a correlate to delineating a species-associated disease spectrum. J. Clin. Microbiol. 19, 44-47.

Janda, S., Young, A., Fitzgerald, J. M., Etminan, M., and Swiston, J. (2010). The effect of statins on mortality from severe infections and sepsis: a systematic review and meta-analysis. J. Crit. Care. 25, 656.e7-656.e22. doi: $10.1016 /$ j.jcrc.2010.02.013

Kirke, D. F., Swift, S., Lynch, M. J., and Williams, P. (2004). The Aeromonas hydrophila LuxR homologue AhyR regulates the $\mathrm{N}$-acyl homoserine lactone synthase, AhyI positively and negatively in a growth phase-dependent manner. FEMS Microbiol. Lett. 241, 109-117. doi: 10.1016/j.femsle.2004.10.011

Larsen, R. A., Wilson, M. M., Guss, A. M., and Metcalf, W. W. (2002). Genetic analysis of pigment biosynthesis in Xanthobacter autotrophicus Py2 using a new, highly efficient transposon mutagenesis system that is functional in a wide variety of bacteria. Arch. Microbiol. 178, 193-201. doi: 10.1007/s00203-0020442-2

Litwin, C. M., and Calderwood, S. B. (1993). Role of iron in regulation of virulence genes. Clin. Microbiol. Rev. 6, 137-149.

Maltz, M., and Graf, J. (2011). The type II secretion system is essential for erythrocyte lysis and gut colonization by the leech digestive tract symbiont Aeromonas veronii. Appl. Environ. Microbiol. 77, 597-603. doi: 10.1128/AEM.01621-10

Morton, D. J., Seale, T. W., Bakaletz, L. O., Jurcisek, J. A., Smith, A., VanWagoner, T. M., et al. (2009). The heme-binding protein (HbpA) of Haemophilus influenzae as a virulence determinant. Int. J. Med. Microbiol. 299, 479-488. doi: 10.1016/j.ijmm.2009.03.004

Morton, D. J., Seale, T. W., Madore, L. L., VanWagoner, T. M., Whitby, P. W., and Stull, T. L. (2007). The haem-haemopexin utilization gene cluster (hxuCBA) as a virulence factor of Haemophilus influenzae. Microbiology 153(Pt 1), 215-224. doi: 10.1099/mic.0.2006/000190-0

Mouriño, S., Rodríguez-Ares, I., Osorio, C. R., and Lemos, M. L. (2005). Genetic variability of the heme uptake system among different strains of the fish pathogen Vibrio anguillarum: identification of a new heme receptor. Appl. Environ. Microbiol. 71, 8434-8441. doi: 10.1128/AEM.71.12.8434-8441.2005

Nadler, K. D., Johnston, A. W., Chen, J. W., and John, T. R. (1990). A Rhizobium leguminosarum mutant defective in symbiotic iron acquisition. J. Bacteriol. $172,670-677$.

Najimi, M., Lemos, M. L., and Osorio, C. R. (2008). Identification of siderophore biosynthesis genes essential for growth of Aeromonas salmonicida under iron limitation conditions. Appl. Environ. Microbiol. 74, 2341-2348. doi: 10.1128/AEM.02728-07

Neilands, J. B. (1994). Identification and isolation of mutants defective in iron acquisition. Methods Enzymol. 235, 352-356. doi: 10.1016/00766879(94)35153-8

Nelson, M. C., Bomar, L., and Graf, J. (2015). Complete genome sequence of the novel leech symbiont Mucivorans hirudinis M3T. Genome Announc. 3:e153014. doi: 10.1128/genomeA.01530-14

Nelson, M. C., Morrison, M., Schanbacher, F., and Yu, Z. (2012). Shifts in microbial community structure of granular and liquid biomass in response to changes to infeed and digester design in anaerobic digesters receiving food-processing wastes. Bioresour. Technol. 107, 135-143. doi: 10.1016/j.biortech.2011. 12.070

O’Malley, S. M., Mouton, S. L., Occhino, D. A., Deanda, M. T., Rashidi, J. R., Fuson, K. L., et al. (1999). Comparison of the heme iron utilization systems of pathogenic vibrios. J. Bacteriol. 181, 3594-3598.
Ochman, H., Gerber, A. S., and Hartl, D. L. (1988). Genetic applications of an inverse polymerase chain reaction. Genetics 120, 621-623.

Ochman, H., Worobey, M., Kuo, C.-H., Ndjango, J.-B. N., Peeters, M., Hahn, B. H., et al. (2010). Evolutionary relationships of wild hominids recapitulated by gut microbial communities. PLoS Biol. 8:e1000546. doi: 10.1371/journal.pbio.1000546

Rio, R. V. M., Anderegg, M., and Graf, J. (2007). Characterization of a catalase gene from Aeromonas veronii, the digestive-tract symbiont of the medicinal leech. Microbiology 153(Pt 6), 1897-1906. doi: 10.1099/mic.0.2006/003020-0

Runyen-Janecky, L. J. (2013). Role and regulation of heme iron acquisition in gram-negative pathogens. Front. Cell. Infect. Microbiol. 3:55. doi: 10.3389/fcimb.2013.00055

Sambrook, J., and Russell, D. W. (2001). Molecular Cloning: a Laboratory Manual. New York, NY: Cold Spring Harbor.

Sawyer, R. (1986). Leech Biology and Behaviour. Vol. 2. Feeding Biology, Ecology, and Systematics. Suffolk: Clarendon Press.

Schwyn, B., and Neilands, J. B. (1987). Universal chemical assay for the detection and determination of siderophores. Anal. Biochem. 160, 47-56. doi: 10.1016/0003-2697(87)90612-9

Senderovich, Y., Gershtein, Y., Halewa, E., and Halpern, M. (2008). Vibrio cholerae and Aeromonas: do they share a mutual host? Isme J. 2, 276-283. doi: 10.1038/ismej.2007.114

Septer, A. N., Wang, Y., Ruby, E. G., Stabb, E. V., and Dunn, A. K. (2011) The heme-uptake gene cluster in Vibrio fischeri is regulated by Fur and contributes to symbiotic colonization. Environ. Microbial. 13, 2855-2864. doi: 10.1111/j.1462-2920.2011.02558.x

Silver, A. C., and Graf, J. (2009). Prevalence of genes encoding the type three secretion system and the effectors AexT and AexU in the Aeromonas veronii group. DNA Cell. Biol. 28, 383-388. doi: 10.1089/dna.2009.0867

Silver, A. C., Kikuchi, Y., Fadl, A. A., Sha, J., Chopra, A. K., and Graf, J. (2007b). Interaction between innate immune cells and a bacterial type III secretion system in mutualistic and pathogenic associations. Proc. Natl. Acad. Sci. U.S.A. 104, 9481-9486. doi: 10.1073/pnas.0700286104

Silver, A. C., Rabinowitz, N. M., Kuffer, S., and Graf, J. (2007a). Identification of Aeromonas veronii genes required for colonization of the medicinal leech, Hirudo verbana. J. Bacteriol. 189, 6763-6772. doi: 10.1128/JB.00685-07

Skorupski, K., and Taylor, R. K. (1996). Positive selection vectors for allelic exchange. Gene 169, 47-52. doi: 10.1016/0378-1119(95)00793-8

Stabb, E. V., and Ruby, E. G. (2002). RP4-based plasmids for conjugation between Escherichia coli and members of the Vibrionaceae. Methods Enzymol. 358, 413-426. doi: 10.1016/S0076-6879(02)58106-4

Steinert, M., Hentschel, U., and Hacker, J. (2000). Symbiosis and pathogenesis: evolution of the microbe-host interaction. Naturwissenschaften 87, 1-11. doi: $10.1007 / \mathrm{s} 001140050001$

Stojiljkovic, I., and Perkins-Balding, D. (2002). Processing of heme and heme-containing proteins by bacteria. DNA Cell. Biol. 21, 281-295. doi: 10.1089/104454902753759708

Telford, J. R., Leary, J. A., Tunstad, L. M. G., Byers, B. R., and Raymond, K. N. (1994). Amonabactin: characterization of a series of siderophores from Aeromonas hydrophila. J. Am. Chem. Soc. 116, 4499-4500. doi: 10.1021/ja00089a058

Worthen, P. L., Gode, C. J., and Graf, J. (2006). Culture-independent characterization of the digestive-tract microbiota of the medicinal leech reveals a tripartite symbiosis. Appl. Environ. Microbiol. 72, 4775-4781. doi: 10.1128/AEM.00356-06

Zywno, S. R., Arceneaux, J. E., Altwegg, M., and Byers, B. R. (1992). Siderophore production and DNA hybridization groups of Aeromonas spp. J. Clin. Microbiol. 30, 619-622.

Conflict of Interest Statement: The authors declare that the research was conducted in the absence of any commercial or financial relationships that could be construed as a potential conflict of interest.

Copyright (c) 2015 Maltz, LeVarge and Graf. This is an open-access article distributed under the terms of the Creative Commons Attribution License (CC BY). The use, distribution or reproduction in other forums is permitted, provided the original author(s) or licensor are credited and that the original publication in this journal is cited, in accordance with accepted academic practice. No use, distribution or reproduction is permitted which does not comply with these terms. 